\title{
Fluorescent aminoglycoside antibiotics and methods for accurately monitoring uptake by bacteria
}

\author{
Mahnaz Sabeti Azad ${ }^{\dagger}$, Maho Okuda ${ }^{\dagger, \dagger}$, Mélina Cyrenne ${ }^{\dagger}$, Mickael Bourge ${ }^{\dagger}$, Marie-Pierre Heck ${ }^{\S}$, Satoko \\ Yoshizawa $^{\dagger}$, and Dominique Fourmy*, ${ }^{\dagger}$. \\ ${ }^{\dagger}$ Université Paris-Saclay, CEA, CNRS, Institute for Integrative Biology of the Cell (I2BC), 91198, Gif-sur-Yvette, France. \\ ${ }^{\S}$ Université Paris-Saclay, CEA, Service de Chimie Bio-organique et de Marquage, 91191 Gif-sur-Yvette, France. \\ Email: dominique.fourmy@i2bc.paris-saclay.fr
}

\begin{abstract}
Characterizing how multidrug-resistant bacteria circumvent the action of clinically used or novel antibiotics requires a detailed understanding of how the antibiotics interact with and cross bacterial membranes to accumulate in the cells and exert their action. When monitoring the interactions of drugs with bacteria it remains challenging to differentiate functionally relevant internalized drug levels from non-specific binding. Fluorescence is a method of choice for observing dynamics of biomolecules. In order to facilitate studies involving aminoglycoside antibiotics, we have generated fluorescently labeled aminoglycoside derivatives with uptake and bactericidal activities similar, albeit with a moderate loss, to those of the parent drug. The method combines fluorescence microscopy with fluorescence-activated cell sorting (FACS) using neomycin coupled to non-permeable cyanine dyes. Fluorescence imaging allowed membrane-bound antibiotic to be distinguished from molecules in the cytoplasm. Patterns of uptake were assigned to different populations in the FACS analysis. Our study illustrates how fluorescent derivatives of an aminoglycoside enable a robust characterization of the three components of uptake: membrane binding, EDPI, and EDPII. Because EDPI levels are weak compared to the two other types of accumulation and critical for the action of these drugs, the three components of uptake must be taken into account separately when drawing conclusions about aminoglycoside function.
\end{abstract}

Keywords: Fluorescence; antibiotics; aminoglycosides; uptake; flow cytometry; microscopy.

Aminoglycosides are among the oldest antibiotics in clinical use. These broad spectrum antibiotics are used against clinically important bacteria and for treatment of infections caused by multidrug-resistant bacteria. ${ }^{1,2}$ In the past decade, novel aminoglycosides have been developed with decreased toxicity and susceptibility to resistance. ${ }^{2-7}$ Many widely used aminoglycosides contain a deoxystreptamine ring (2-DOS) that is essential for antimicrobial activity. The 2-DOS aminoglycosides bind both subunits of the ribosome and inhibit protein synthesis. ${ }^{8-10}$ These drugs cause miscoding ${ }^{11}$ via a direct interaction with ribosomal RNA (rRNA) of the small subunit. ${ }^{10,12-16}$ Some 2-DOS aminoglycosides also interact at a specific site within the large ribosomal subunit resulting in inhibition of translocation ${ }^{17,18}$ or recycling. ${ }^{19}$ In addition, aminoglycosides have been reported to inhibit initiation ${ }^{20,21}$ and perturb ribosome biogenesis. ${ }^{22-24}$

Aminoglycoside uptake occurs through two energydependent phases known as EDPI and EDPII. ${ }^{25-27}$ EDPI is known to be dependent on the proton motive force (PMF). ${ }^{28-}$ ${ }^{30}$ EDPII requires active protein synthesis by aminoglycoside-sensitive ribosomes and, therefore, is energy dependent. The lethal mode of action of aminoglycosides is thought to occur through induction of ribosomal miscoding, which produces misfolded proteins that when inserted into the inner membrane trigger an increase of permeability and consequently a diffusive entry of the drug in EDPII. ${ }^{31}$ Increase in cell killing efficiency is interpreted as an increase in aminoglycoside uptake. Measuring aminoglycoside uptake is im- portant for understanding the basis of aminoglycoside action. This has been often achieved by study of cultured cells treated with radioactively labeled aminoglycosides. ${ }^{25,26,32} \mathrm{~A}$ method has been reported for measuring intracellular levels of kanamycin that relies on an ELISA, but it requires cell lysis. ${ }^{33}$ Novel tools making use of fluorescent antibiotics are emerging that enable characterization of the interactions of antibiotics with bacteria at the level of organelles or even whole organisms. ${ }^{34}$ For example, gentamicin and tobramycin coupled to Texas Red have been widely used in this type of analysis; however this dye, by itself, penetrates cells, complicating analysis. ${ }^{35}$ Recently developed techniques make use of spectrofluorimetry, microspectrofluorimetry and kinetics microspectrofluorimetry for single-cell analysis of naturally fluorescent antibiotics or fluorescently-labeled compounds. ${ }^{36,37}$ In addition, mass spectrometry was combined with spectrofluorimetry to provide insights into the efflux mechanisms of fluoroquinolones. ${ }^{38}$

Depending on the analysis, the membrane-bound fraction of a drug may be quantified, biasing the measurement of true internalized drug levels. For aminoglycosides, it is also important to differentiate EDPI and EDPII phases, as only EDPI leads to cell death. EDPII is a consequence of internalization of the drug through the membrane damaged due to EDPI. In addition, because each cell may respond differently to antibiotics, an accurate description of drug uptake requires single-cell analysis. To finely evaluate aminoglycoside uptake, we developed a series of cyanine-modified neomycin 


\begin{tabular}{|c|c|c|}
\hline & Neomycin & Neo-Cy5 \\
\hline P. aeruginosa PA14 & 3.25 & 150 \\
\hline
\end{tabular}

Measured in minimal medium MOPS-G.

Neo-Cy5 causes misreading during ribosomal decoding. Aminoglycosides cause miscoding in vitro at concentrations in the range of $10-100 \mu \mathrm{M} .{ }^{5,11,43,44}$ Since Neo-Cy5 binds the ribosomal decoding site on the small subunit (Figure 2(a)), we tested the capacity of Neo-Cy5 to induce misreading using a dual-luciferase gain-of-function assay. In this assay, misreading restores the enzymatic activity of a mutant firefly luciferase. In the mutant, codon 245, which in the wild-type mRNA is CAC (coding for histidine), is replaced by the near-cognate CGC codon (arginine). ${ }^{5}$ Translation activity was analyzed by comparison to the signal due to wild-type Renilla luciferase, which served as internal standard. Like neomycin, Neo-Cy5 caused miscoding however effects were attenuated by more than one order of magnitude (Figure 2(b)).

a)
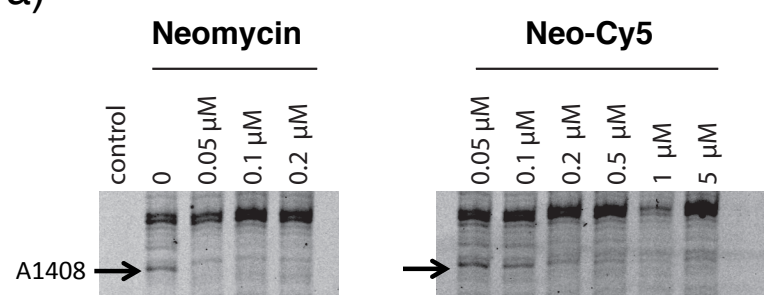

b)

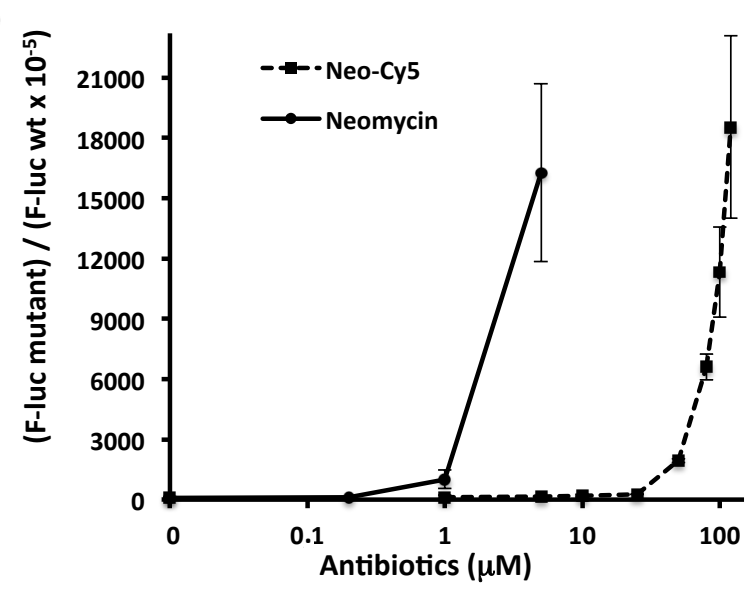

Figure 2. Neo-Cy5 binds ribosomal A site and induces misreading. a) Binding of neomycin (left) and Neo-Cy5 (right) to ribosomes was assayed using DMS chemical probing. Left lane is a control reaction with no DMS added. Right lanes are reactions in the presence of increasing concentrations of neomycin or Neo-Cy5. The protected nucleotide A1408 that belongs to the neomycin binding site (Figure 1(b) is marked with an arrow. b) Mis-incorporation of amino acids was assayed using a gain-offunction assay. Wild-type and mutant firefly luciferase reporters were used for in vitro translation reactions together with the Renilla luciferase, which served as an internal control. Error bars are s. e. m. for three independent experiments.

Neo-Cy5 has proton motive force-dependent bactericidal activity. Aminoglycoside accumulation in bacterial cells is known to be dependent on PMF. ${ }^{28}$ We therefore tested the effect of the protonophore carbonyl cyanide m-chlorophenyl hydrazone (CCCP) on Neo-Cy5-induced bacterial cell death. Addition of CCCP protected cells from the drug-induced killing (Figure 3 and Figure S8), demonstrating that, as for other aminoglycosides, the accumulation of Neo-Cy5 is PMF dependent.

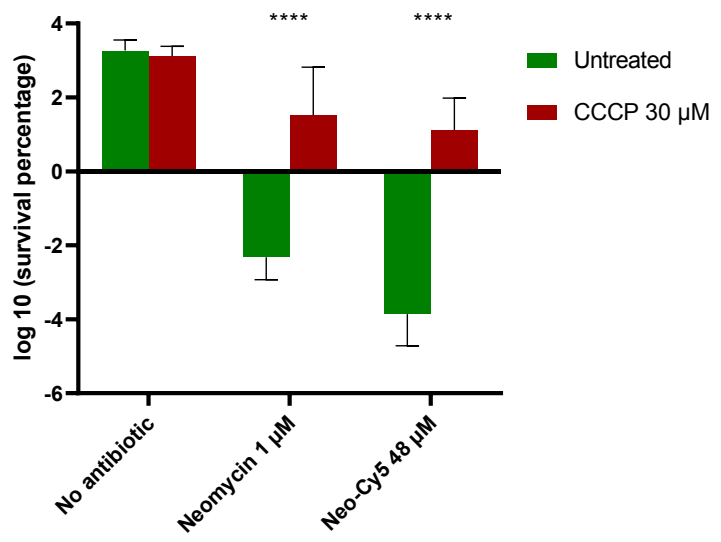

Figure 3. Neo-Cy5-induced cell killing is PMF dependent. Survival of $E$. coli MG1655 cells after a 4.5-h treatment with 1.5 $\mu \mathrm{M}$ neomycin or $48 \mu \mathrm{M}$ Neo-Cy5 with and without a 2 -h preincubation with $30 \mu \mathrm{M}$ CCCP. Plotted are values relative to untreated control culture. Error bars are s. e. m. and were calculated from three independent experiments. Significant differences, calculated by the Mann-Whitney test, are indicated $(* * * *$ $\mathrm{P}<0.0001)$.

FACS and TIRF microscopy reveal drug peripheral accumulation and strong interaction with membranes. Because cationic aminoglycosides can interact with the membranes of the bacterial cell surface, we devised a protocol to measure only tightly-bound or internalized Neo-Cy5. We first removed weakly membrane-bound and not internalized molecules by washing the cells on mixed cellulose ester filters. At least three washes with MOPS-G at $37{ }^{\circ} \mathrm{C}$ were necessary to remove non-internalized drug (Figure S9). We measured Neo-Cy5 uptake by E. coli MG1655 cells in the exponential phase of growth in the presence of Neo-Cy5 at a concentration three times the MIC. After filtration, cells were recovered and immediately analyzed by FACS. After a short 5-minute exposure to Neo-Cy5, a signal due to the conjugate was clearly distinguished from the background fluorescence (Figure 4(a)). We verified that the signal was dependent on the neomycin moiety: TIRF microscopy showed that the Cy5 dye alone was not incorporated into live bacterial cells and that $\mathrm{Cy} 5$ did not interact strongly with membranes (Figure S10 and Figure 4(a)). Because the observed signal for Neo-Cy5 could correspond to molecules tightly bound to the membrane or internalized in the periplasm or cytoplasm, we inspected the localization of the drug by TIRF microscopy (Figure 4(b)). Here, periplasmic accumulation would correspond to the self-promoted mechanism previously proposed where aminoglycoside cross irreversibly the outer membrane via the lipopolysaccharides in E. coli. ${ }^{45}$ After a 5-minute incubation, Neo-Cy5 accumulated at the periphery of the cell and did not overlap with the fluorescence of Spinach-tagged ribosomes ${ }^{46}$ (Figure 4(c) and Figure S11)). We conclude that Neo-Cy5 bound at the membrane of a cell or internalized in the periplasm can readily be 
derivatives that have antibacterial activity similar to the parent aminoglycoside. When used with adequate protocols, these derivatives allow single-cell analysis of aminoglycoside uptake by fluorescence microscopy and fluorescenceactivated cell sorting (FACS).

\section{RESULTS AND DISCUSSION}

Generation of Neo-cyanine derivatives. Radioactivity based assays $^{25,26,32}$ and ELISA ${ }^{33}$ do not report on accumulation at the single cell level. A fluorescent derivative with preserved uptake and bactericidal activities would facilitate analysis of uptake with single-cell resolution. We previously showed that the 5" position of neomycin could be modified with various functional groups without compromising antimicrobial activity (Figure S1). Analysis of the structures of a neomycin-ribosome complex indicated that functional groups introduced at this position are accommodated in the major groove of helix 44 of the $16 \mathrm{~S}$ rRNA in a conformation that does not interfere with drug binding or induction of miscoding.

We used a derivative of neomycin where the hydroxyl group at the 5" position was substituted with $\mathrm{S}-\left(\mathrm{CH}_{2}\right)_{2}-\mathrm{NH}_{2}$ to allow introduction of extra chemical groups by coupling (Supporting information, product 5). ${ }^{39}$ Addition of a thyminylacetamidoethylthio or uracil (Neo-U) at the 5" position preserved the antimicrobial activity against $E$. coli as measured using an MIC assay (Figure S1 and Table S1). As expected, Neo-U bound to the A site on the small ribosomal subunit, although affinity was slightly decreased compared to the unmodified neomycin (Figure S2). This result indicated that large chemical modifications can be introduced at the 5 " position of ring III without strongly perturbing A-site binding or antimicrobial properties.

We next labeled neomycin with sulfonated cyanines Cy3 and Cy5 (Figures S3,S4,S5 and S6), which are non-membrane permeable dyes suitable for fluorescence microscopy. ${ }^{40}$ The spectral properties of Neo-Cy5 conjugate (Figure 1(a)) do not differ from those of the free dye (Figure S7). We verified that the fluorescent probes are accommodated without any steric clash by docking into the crystal structure of $E$. coli ribosomes bound to neomycin (PDB code 4v52). The Cy3 and $\mathrm{Cy} 5$ probes, which are bulkier than the uracil base, likely lie in a cavity between helices $\mathrm{h} 27$ and h44 of $16 \mathrm{~S}$ ribosomal RNA (Figure 1(b)).

a)

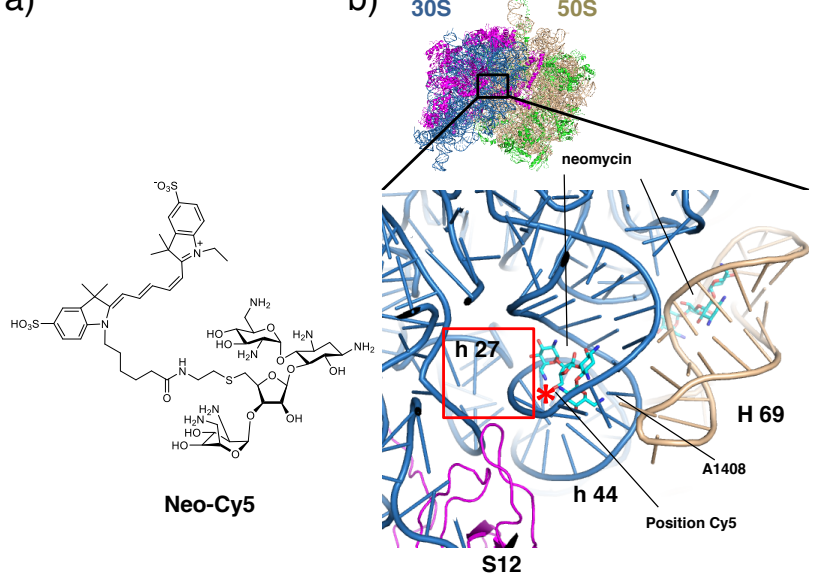

Figure 1. Structure of the Neo-Cy5 conjugate and accommodation at the ribosomal A site. a) Structure of Neo-Cy5 in which Cy5 is coupled to ring III of neomycin. b) Neomycin binding sites in h44 of the small ribosomal subunit (blue) and in H69 of the large ribosomal subunit (beige) (PDB code 4v52). Small and large ribosomal proteins are shown in purple and green, respectively. The red box indicates a cavity near the neomycin binding site in h44 where Cy5 can be accommodated. Nucleotide A1408 that is part of the neomycin binding site is indicated.

Neo-cyanine derivatives are active antibiotics. Next, we verified that Neo-Cy5 binds the decoding site of $16 \mathrm{~S}$ rRNA in $70 \mathrm{~S}$ ribosomes. Footprinting analysis of ribosomal particles bound to Neo-Cy5 showed that the conjugate interacts with the decoding site of the small ribosomal subunit in a manner similar to neomycin and Neo-U, and like Neo-U, Neo-Cy5 has slightly lower affinity than the parent antibiotic (Figure 2(a)). We next tested the antimicrobial activity of Neo-Cy5. The measured MIC in minimal medium was slightly higher than that of neomycin (Table 1) and similar to the MICs for Neo-U (Table S1) and closely related aminoglycosides. ${ }^{41,42}$ The MIC of Neo-Cy3 was also similar to that of Neo-Cy5 (Table 1).

MIC values were also measured in Mueller-Hinton broth for Gram negative and positive bacteria including ESKAPE pathogens (Table 2). Tested strains included clinically relevant Gram negative pathogens such as Pseudomonas aeruginosa, A. baumannii, K. pneumoniae, S. typhimurium, as well as the Gram positive $S$. aureus USA300. MIC values for the parental drug neomycin were higher in rich medium when compared to minimal medium. This effect was stronger for the Neo-Cy5 conjugate as MIC values were increased by factors ranging from 20 to 40 compared to the values measured for neomycin (Table 2). The MIC value was not measurable for Pseudomonas aeruginosa in rich medium and found to be $150 \mu \mathrm{g} / \mathrm{ml}$ in MOPS-G (Table 3).

Table 1. MIC values in $\mu \mathrm{g} / \mathrm{ml}$ of neomycin-cyanine derivative conjugates against $E$. coli MG1655.

\begin{tabular}{|c|c|c|c|}
\hline & Neomycin & Neo-Cy5 & Neo-Cy3 \\
\hline M9 medium & 3.0 & 13 & ND \\
\hline MOPS medium & 1.1 & 10.4 & 5.2 \\
\hline
\end{tabular}

Measured in minimal medium MOPS-G. ND: not determined.

Table 2. MIC values of Neo-Cy5 in $\mu \mathrm{g} / \mathrm{ml}$ against Gram negative and positive strains.

\begin{tabular}{|c|c|c|}
\hline & Neomycin & Neo-Cy5 \\
\hline E. coli MG1655 & 2.5 & 75 \\
\hline P. aeruginosa PA14 & 2.5 & $>150$ \\
\hline A. baumannii DSM30011 & 5.0 & 75 \\
\hline K. pneumoniae LM21 & 1.25 & 25 \\
\hline S. typhimurium 14028 & 1.25 & 50 \\
\hline B. subtilis & 0.25 & 6.25 \\
\hline M. luteus & 1.5 & 6.25 \\
\hline S. aureus USA300 & 2.5 & 75 \\
\hline
\end{tabular}

Measured in cation-adjusted Mueller-Hinton broth.

Table 3. MIC values of Neo-Cy5 in $\mu \mathrm{g} / \mathrm{ml}$ against $P$. aeruginosa PA14. 
detected by FACS and visualized by TIRF fluorescence microscopy.

Neo-Cy5 binding to bacterial membranes is saturable. Binding of Neo-Cy5 to the bacterial membranes was found to be instantaneous as visualized in real time by FACS (Figure $\mathrm{S} 12$ ). Membranes of $E$. coli showed saturability when exposed for 5 minutes to increasing concentrations of NeoCy5 (Figure 4(d,e)). At low concentrations, there was strong heterogeneity in fluorescence levels of individual cells (Figure $4(\mathrm{~d}))$. At the highest concentrations, even though the exposure time was short to ensure that only the drug interaction with the membrane was monitored, in a fraction of cells high levels of uptake was observed (Figure 4(d)). Experiments described in the next section demonstrated that this fraction corresponds to cells with cytoplasmic uptake. In cells treated with $64 \mu \mathrm{M}$ of Neo-Cy5, $2.9 \%$ of cells had detectable levels of Neo-Cy5 in the cytoplasm. This value is above the known fraction of $0.3 \%$ of cells that are dead in a fast growing bacterial population. ${ }^{47}$ Therefore there is rapid cytoplasmic uptake at high concentrations of Neo-Cy5.

Neo-Cy5 is internalized mainly through EDPII. E. coli MG1655 cells were treated with $32 \mu \mathrm{M}$ Neo-Cy5 for 30 minutes, the time period corresponding to the onset of aminoglycoside-induced exponential killing. ${ }^{48}$ When cells were imaged using TIRF, we observed that fluorescence signals were distributed over the entire cell volume for most of the cells (time $30 \mathrm{~min} 88 \%, \mathrm{n}=57$ ), (Figure 5(a)). This clearly indicated cytoplasmic uptake. Most of the cells had low levels of fluorescence corresponding to EDPI uptake. A low percentage of cells had bright Cy5 fluorescence signals sug- gestive of EDPII accumulation. For $60 \mathrm{~min}$ of incubation, $100 \%$ of the cells had cytoplasmic uptake $(n=119)$. Cells exposed to Neo-Cy5 overnight showed morphological defects (Figure S13) similar to what has been previously described for cells treated with aminoglycosides, ${ }^{49,50}$ in particular foci formation at poles.

Addition of the protein synthesis inhibitor chloramphenicol prior to exposure to aminoglycosides decreases EDPI and abolishes EDPII. ${ }^{51}$ We pre-incubated the cells with chloramphenicol before the addition of a lethal concentration of NeoCy5 to evaluate the contributions of EDPI and EDPII uptake by FACS (Figure 5(b)). Differences in profiles obtained with or without chloramphenicol were very minor at 30 minutes; TIRF imaging showed that EDPI already occurred for most of the cells (Figure 5(a)). Only a slight shift of the distribution toward stronger levels of fluorescence was observed with time. This result revealed that EDPI uptake is indeed difficult to capture by FACS. The shift of the distribution in absence of chloramphenicol was more pronounced at 60 and 150 minutes in agreement with an EDPII-driven cytoplasmic uptake. We concluded that little Neo-Cy5 accumulates in the cytoplasm via EDPI when compared to membrane-bound or cytoplasmic levels that resulted from the EDPII-driven process.

Accumulation of Neo-Cy5 and loss of cell viability. We next performed a detailed kinetic analysis of Neo-Cy5 uptake at the single-cell level. Cell viability was monitored in parallel. Like observed for other aminoglycosides ${ }^{48}$, NeoCy5 displayed the characteristic lag followed by exponential killing of the cells (Figure 5(c)). The plot of the sum of the fluorescence levels as a function of time calculated from our 

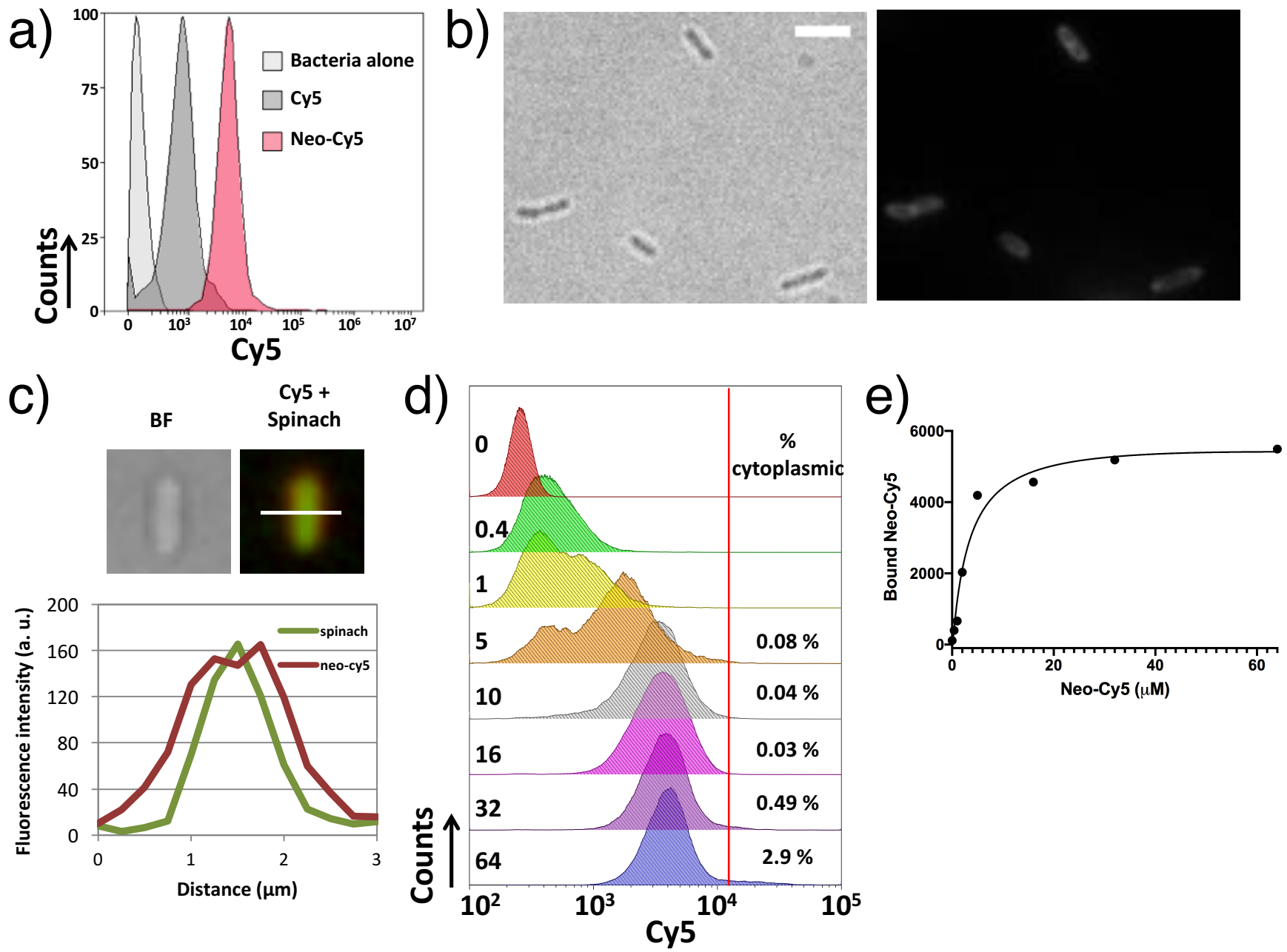

Figure 4. Fluorescence microscopy and FACS enable detection of Neo-Cy5 bound to E. coli MG1655 cells. a) FACS analysis of cells exposed to $32 \mu \mathrm{M} \mathrm{Cy} 5,32 \mu \mathrm{M}$ Neo-Cy5, or no dye for $5 \mathrm{~min}$ at $37^{\circ} \mathrm{C}$. Cells were washed on a $0.45 \mu \mathrm{m}$-pore-size HAWP membrane filter. Binding of Neo-Cy5 was clearly distinct from cellular autofluorescence and residual binding of the free dye. b) Representative brightfield and TIRF microscopy images of cells incubated for 5 min with Neo-Cy5 as in panel "a". Scale bar: $5 \mu$ m c) Neo-Cy5 does not localize with ribosomes after a 5-minute incubation. E. coli cells expressing Spinach-tagged ribosomes were exposed to Neo-Cy5 and imaged. Left: Brightfield. Right: Neo-Cy5 (red), Spinach (green). Bottom: plot of a cross section of fluorescence signal for a representative cell with the peripheral pattern. d) Saturability of bacterial membranes to Neo-Cy5 binding. Cells were incubated for 5 min at $37{ }^{\circ} \mathrm{C}$ with increasing concentrations of Neo-Cy5, filtered, and analyzed by FACS. The percentage of cells with cytoplasmic uptake was calculated from the number of cell counts with a Cy5 signal higher than the red threshold line divided by the total number of cell counts. e) Binding curve of the membrane-bound Neo-Cy5.

single-cell analysis recapitulated previous data obtained on cell ensembles. ${ }^{26}$ During the first 20 minutes of incubation with the drug, fluorescence levels increased slightly while cell survival remained intact. During this period, Neo-Cy5 localized at the cell periphery (Supplementary Figure 13). At 40 minutes, the cytoplasmic pattern became dominant with stronger drug accumulation (Figure 5(c,d) and Figure S14) concomitantly with the onset of the decrease in cell survival rate (Figure $5(\mathrm{c})$ ). This period corresponded to a transition between EDPI and EDPII. The onset of EDPII was previously considered to be the first time point at which uptake becomes linear and rapid. ${ }^{26}$ This time point for Neo-Cy5 was around 50 minutes (Figure 5(c)). During the 20-minute transition period (40 to $60-\mathrm{min}$ ) $90 \%$ of the cells lost viability with a sharp increase in drug uptake. After 80 minutes, 99\% of the cells were dead and levels of accumulation continued to increase steeply and linearly during 40 minutes, reaching a factor of approximately 10 of increase taking as a reference the membrane-bound fraction (ratio of medians $120 \mathrm{~min} / 5$ min) (Figure 5(c)). Finally, at the beginning of the transition time point (40 minutes), the cytoplasmic drug levels that accumulated during EDPI, accounted for approximately one third of the total levels, the other two thirds corresponded to membrane/periplasmic interaction or accumulation (Figure $5(\mathrm{c}))$.

\section{CONCLUSIONS}

With the purpose of improving methodologies for measuring aminoglycoside uptake by bacteria we used click chemistry to develop fluorescent conjugates of neomycin that have uptake and bactericidal properties similar to the ones of the parent aminoglycoside. We coupled sulfonated cyanine dyes that are not membrane-permeable to neomycin allowing clear visualization of the uptake. The obtained Neo-Cy3 and Neo-Cy5 derivatives exhibited uptake properties strictly 

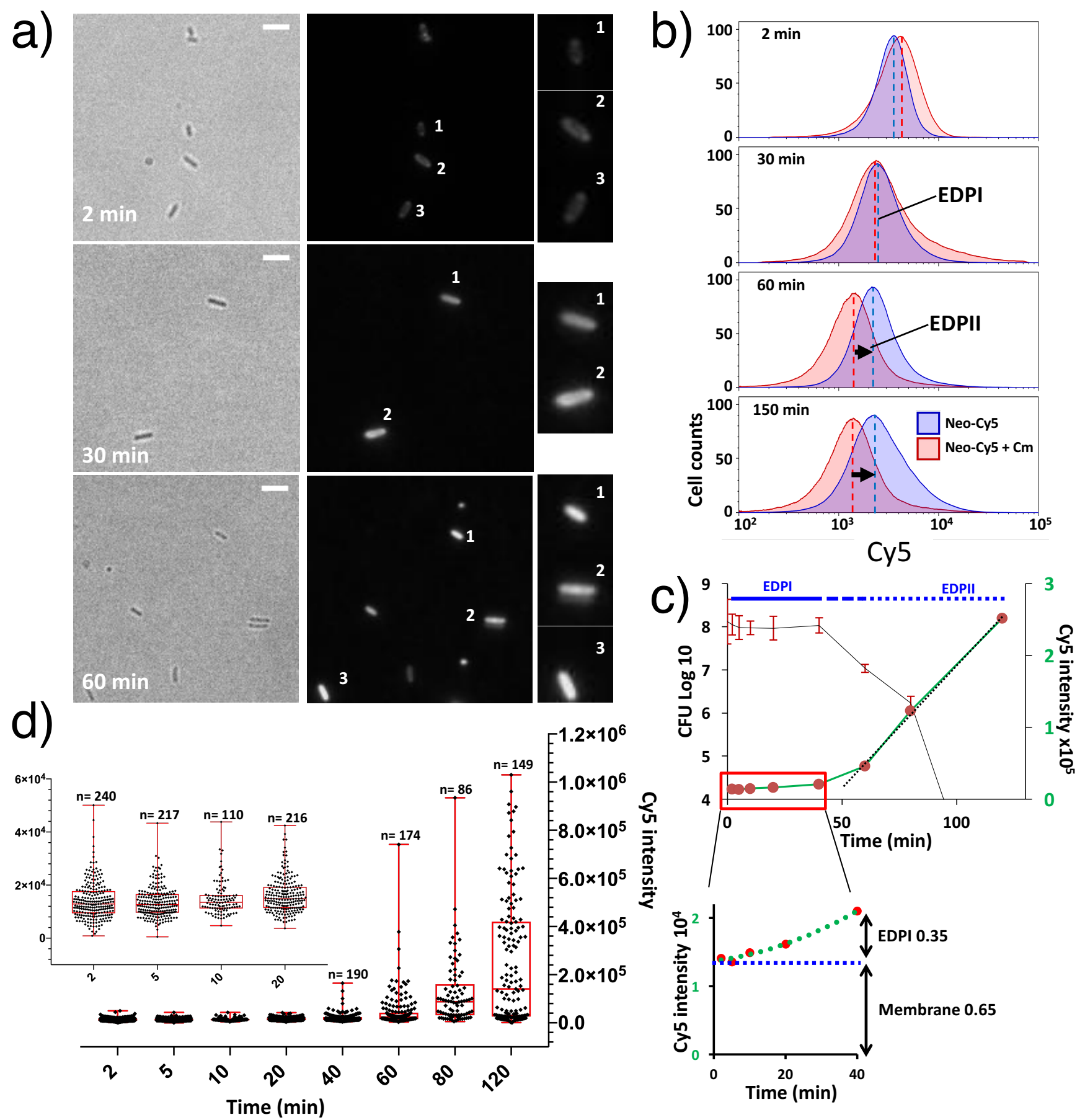

Figure 5. EDPI-mediated uptake can be distinguished from EDPII-mediated uptake. a) Representative brightfield and TIRF microscopy images of cells after 2, 30 and 60 min of exposure to $32 \mu \mathrm{M} \mathrm{Neo-Cy5}$. Scale bar: $5 \mu \mathrm{m} \mathrm{b}$ ) E. coli cells treated with $32 \mu \mathrm{M}$ Neo-Cy5 with or without $25 \mu \mathrm{g} / \mathrm{mL}$ of chloramphenicol were incubated for the times indicated. At each time point, cells were filtered, washed, and analyzed by FACS. Cell counts were normalized to $100 \%$. Weak cytoplasmic uptake, which corresponded to EDPI was detected as an upper shift of the blue population compared to the red population. The stronger shift corresponding to EDPII levels of uptake is highlighted by an arrow. c) Killing curve obtained for E. coli with monitoring of Neo-Cy5 uptake. Cells were grown exponentially at $37^{\circ} \mathrm{C}$ in MOPS medium containing glucose to an $\mathrm{OD}_{600}$ of 0.2 , diluted 10 times in fresh medium before addition of Neo-Cy5. At different time points, cells were collected and filtered to remove drug excess. Cells were plated on agar pads for fluorescence microscopy (Figure S14) and fluorescence quantification to generate panel $d$ and serial dilutions were made and plated on LB agar for c.f.u. counting. The kinetic of Neo-Cy5 uptake on the cell population is represented by the sum of the single-cell analysis of fluorescence signals displayed in panel d. The rapid and linear EDPII phase is highlighted by a dashed line. d) Single-cell quantification of Neo-Cy5 accumulation as a function of time. Red lines highlight the medians, boxes show $75 / 25 \%$, and vertical dashed lines indicate $90 / 10 \%$ of the maxima. 
dependent on the neomycin moiety demonstrating that this type of conjugate can be widely used to report on aminoglycoside uptake. In addition, these dyes have spectral properties that make them suitable for fluorescence microscopy. The Neo-Cy5 conjugate is active against Gram-positive and negative strains with the exception of Pseudomonas aeruginosa in rich medium. This pathogen is known to resist to multiple drugs owing to a membrane of low permeability, the expression of multidrug efflux pumps and its adaptation to the presence of antibiotics. The efflux pump MexXMexY-OprM plays a role in intrinsic resistance to aminoglycosides. $^{52-54}$ The pump has moderate drug specificity as aminoglycosides, macrolides and tetracycline are substrates. $^{55}$ Structural data obtained for this type of pumps provided details on their architecture and revealed indeed multiple binding pockets for various drugs. ${ }^{56-58}$ It remains to be investigated if the presence of the fluorescent dye will affect the efflux mechanism in Pseudomonas aeruginosa.

Using Neo-Cy5 conjugate, we devised a method for accurate monitoring of aminoglycoside uptake. Membrane binding of $\mathrm{Neo}-\mathrm{Cy} 5$ was found to account for a large fraction of the fluorescence signal. We showed that we could remove the excess of drug and the weakly bound molecules, which otherwise masked the real levels of uptake, by filtration and washing. Using TIRF microscopy we ensured the validity of FACS observations. Using FACS, we monitored drug binding and intracellular accumulation. Neo-sulfonated-cyanine derivatives did not suffer from dye permeability drawbacks observed for dyes such as Texas Red. ${ }^{35}$

Aminoglycosides are bound to the bacterial cell membrane and accumulate in the cytoplasm of bacterial cells through EDPI and EDPII. The membrane-bound and EDPII components accounted for a large fraction of the total levels of Neo-Cy5 tightly associated with E. coli cells. Levels of NeoCy5 resulting from EDPI-mediated internalization were low even though it is this fraction that results in the deleterious effects of aminoglycosides on cells. The loss of membrane integrity results in the onset of strong diffusive entry of the drug during EDPII. ${ }^{25,27}$

The data reported here illustrate how fluorescent derivatives of an aminoglycoside enable a robust characterization of the three components of uptake: membrane binding, EDPI, and EDPII. EDPII-mediated uptake is a consequence of the miscoding activity of the drug that accumulated via EDPI. As miscoding levels can vary between bacterial strains and between mutants of a single strain, EDPII accumulation may only partially reflect EDPI accumulation. Thus, it is critical that the three components of aminoglycoside uptake be evaluated. We expect that the method described here will be applied to characterize aminoglycoside uptake into bacteria to facilitate a better understanding of the mechanisms of action of these drugs and their next generation derivatives. Interestingly, the group of $\mathrm{Y}$. Tor recently investigated the uptake of several aminoglycoside-Cy3 conjugates including neomycin-Cy3 and guanidinoneomycin-Cy3 in Chinese hamster ovarian cells using fluorescence microscopy and FACS. ${ }^{59}$ Guanidinoglycosides-Cy3 conjugates entered cells better than their parent aminoglycosides. This work together with our results emphasize the usefulness of Cyanineaminoglycoside conjugates for further studies of their cellular uptake by eukaryotic and prokaryotic cells. This class of antibiotics, including neomycin, has recently drawn strong attention for the development of novel, potent, and less toxic drugs to address the pressing societal problem of multidrugresistant (MDR) infectious disease. ${ }^{60,61}$ The approach combining fluorescence microscopy and FACS should provide a framework for future antibiotic-cell interaction studies and facilitate the development of novel aminoglycosides.

\section{METHODS}

Chemicals. Cy5 and Cy3 NHS-esters were purchased from General Electric Healthcare or Lumiprobe GmbH. 3,5Difluoro-4-hydroxybenzylidene imidazolinone was purchased from Lucerna Technologies. 2,2,2-trifluoro-N-(2sulfanylethyl)acetamide was obtained from Merck or prepared following the reported procedure. ${ }^{62}$

Labeling of neomycin with cyanine fluorophores. A derivative of neomycin containing 2-Ntrifluoroacetamidoethylthio in place of a hydroxyl group in ring III was used for functionalization. Other amino groups were protected by hexa-N-tert-butyloxycarbonyl groups for selective reactivity at the new $5 " \mathrm{NH}_{2}$ position. The derivative was used to conjugate neomycin to NHS-ester dyes. Selective deprotection of the 5" position was performed in ammonium hydroxide in methanol, and the unique free amino group was reacted with $\mathrm{Cy} 5$ or Cyanine 5 monofunctional NHS-ester. Reactions were monitored by analytical thinlayer chromatography (TLC) on silica gel 60 F254 plates $(0.25 \mathrm{~mm})$. The Cy5 and Cyanine 5 conjugates were purified on TLC plates (Silica gel 60, Merck), eluted in ethanol, and deprotected with trifluoroacetic acid $(90 \%)$ to remove butyloxycarbonyl groups.

Purification of ribosomes. Tightly coupled $70 \mathrm{~S}$ ribosomes from $E$. coli MRE600 were prepared as described. ${ }^{63,64}$ Briefly, cells were grown in exponential phase and when the $\mathrm{OD}_{600}$ reached 0.3 , cells were collected by centrifugation. Cells were lysed by passage through a module/piston homogenizing system pre-cooled to $-80{ }^{\circ} \mathrm{C}$ that maintains the material in a frozen state. The piston was actuated with a Carver hydraulic press. Ribosomes were isolated by several centrifugation steps followed by a sucrose gradient (10-40\%) fractionation. The fraction containing $70 \mathrm{~S}$ particles was collected using a density gradient fraction system (Teledyne Isco), pelleted, and resuspended in $50 \mathrm{mM}$ Tris- $\mathrm{HCl}(\mathrm{pH}$ 7.6), $10 \mathrm{mM} \mathrm{MgCl}, 100 \mathrm{mM} \mathrm{NH} \mathrm{NH}_{4} \mathrm{Cl}, 6 \mathrm{mM}$ 2mercaptoethanol. Aliquots were stored at $-80{ }^{\circ} \mathrm{C}$ after flash freezing in liquid nitrogen. The ribosome concentration was obtained by measuring the absorption at $260 \mathrm{~nm}$; we assumed that there are 23 pmol ribosomes per $\mathrm{A}_{260}$ unit.

Footprinting of Neo-Cy5 on $70 \mathrm{~S}$ ribosomes. The concentration of Neo-Cy5 stock solution was estimated from the absorbance at $649 \mathrm{~nm}$ measured in $10 \mathrm{mM}$ Tris- $\mathrm{HCl}, \mathrm{pH} 7.5$. Chemical probing of Neo-Cy5-ribosome complexes was performed as described. ${ }^{65}$ We used the RNA base-specific reagent dimethyl sulfate (DMS) which methylates positions $\mathrm{N} 1$ of adenines and N3 of cytidines as well as position N7 of guanines. ${ }^{66}$ Modification reactions $(100 \mu \mathrm{l})$ with $70 \mathrm{~S}$ particles $(10 \mathrm{pmol})$ were performed in a buffer containing $80 \mathrm{mM}$ potassium cacodylate $\mathrm{pH} 7.2,100 \mathrm{mM}$ ammonium chloride, $20 \mathrm{mM}$ magnesium chloride, $1 \mathrm{mM}$ dithiothreitol and 0.5 mM EDTA. In brief, $1 \mu 1$ of (DMS) (1:10 dilution in 95\% ethanol) was added to a $50-\mu \mathrm{L}$ reaction mixture. After incubation at $37{ }^{\circ} \mathrm{C}$ for 10 minute reactions were stopped by addition of $25 \mu \mathrm{L}$ of $6.7 \%(\mathrm{v} / \mathrm{v}) \beta$-mercaptoethanol in 280 
$\mathrm{mM}$ sodium acetate ( $\mathrm{pH} 5.4$ ) and $150 \mu \mathrm{L}$ of ethanol followed by rapid mixing. After precipitation, the pellets were resuspended in $10 \mu \mathrm{L}$ of $\mathrm{H}_{2} \mathrm{O}$.

Sites of modification were analyzed by fluorescent primer extension as previously described. ${ }^{67}$ A Cy5-labeled fluorescent DNA primer was purchased from MWG Biotech. Reverse transcription reactions were performed in $10 \mu \mathrm{L}$ of 50 $\mathrm{mM}$ Tris- $\mathrm{HCl}, \mathrm{pH} 8.3,75 \mathrm{mM} \mathrm{KCl}, 3 \mathrm{mM} \mathrm{MgCl} 210 \mathrm{mM}$ DTT with $0.25 \mathrm{mM}$ each dNTP. SuperScript II (Invitrogen, $0.5 \mu \mathrm{L} 100$ units) was added and reactions were incubated at $45{ }^{\circ} \mathrm{C}$ for $40 \mathrm{~min}$. For sequencing samples, $1.25 \mathrm{mM}$ of ddATP, ddCTP, ddGTP, or ddTTP was added to individual reverse transcription reactions of each sample. Reactions were stopped by ethanol precipitation. cDNA samples were dissolved in $10 \mu \mathrm{L}$ loading solution containing $7 \mathrm{M}$ urea. A small aliquot ( 1.5 to $3 \mu \mathrm{L}$ ) of each sample was loaded on an $8 \%$ polyacrylamide $7 \mathrm{M}$ urea gel for separation of cDNAs. Gels were analyzed on a Typhoon imaging system. Molecular graphics were generated using PyMOL(TM) 2.0.1.

Miscoding assay. Miscoding was assessed in a gain-offunction assay using firefly and Renilla luciferases. DNA reporter plasmids pT7 hFluc WT, pT7 hFluc H245R(CGC), and pT7 hRluc WT for in vitro translation assay were provided by Erik Böttger and Dimitri Scherbakov (University of Zurich). ${ }^{5}$ Wild-type and mutant DNAs were used for in vitro translation reactions together with the Renilla luciferase DNA, which served as an internal control. In vitro translation reactions were performed using the PURExpress system (New England BioLabs). The premix for one reaction contained $2 \mu \mathrm{L}$ solution $\mathrm{A}, 1.5 \mu \mathrm{L}$ solution $\mathrm{B}, 5 \mathrm{nM}$ DNA templates, and 1 unit $/ \mu \mathrm{L}$ of SUPERase $\cdot \mathrm{In}^{\mathrm{TM}}$ RNase Inhibitor (Invitrogen). The reaction was begun by addition of $4 \mu \mathrm{L}$ of the premix lacking aminoglycosides to $1 \mu \mathrm{L}$ of aminoglycoside dilution in $0.2 \mathrm{ml}$ thin-walled tubes on ice. Synthesis was performed at $37{ }^{\circ} \mathrm{C}$ for $35 \mathrm{~min}$ in a thermocycler (lid temperature $98{ }^{\circ} \mathrm{C}$ ) and stopped by placing samples on ice. Luciferase activity was measured using the Dual-Luciferase Reporter Assay System (Promega). Luciferase assay reagent $(50 \mu 1)$ was added to each sample, and the samples were mixed and transferred to a white 96-well plate (Greiner, catalog number 655075) for bioluminescence quantification using an Infinite M200 microplate reader (Tecan). Miscoding was quantified by calculating the mutant firefly/Renilla luciferase activity compared with the wild-type firefly/Renilla luciferase activity.

Minimum inhibitory concentration measurement. The minimum inhibitory concentrations (MICs) were determined using a liquid culture assay according to EUCAST guidelines. Aliquots of an overnight culture of E. coli MG1655 were diluted to have an inoculum of $5.5 \times 10^{5}$ colony-forming units per $\mathrm{mL}$ (c.f.u. $/ \mathrm{mL}$ ) into the medium containing 2-fold serial dilutions of antibiotics. Growth was measured by turbidity at each concentration during $18 \mathrm{~h}$ of incubation at $37{ }^{\circ} \mathrm{C}$. Measurements were performed on $200 \mu \mathrm{L}$ samples in a 96-well microtiter plate with transparent lid using an Infinite M200PRO (TECAN). For Neo-Cy5, turbidity was measured at $400 \mathrm{~nm}$ or $500 \mathrm{~nm}$ instead of $600 \mathrm{~nm}$ to minimize Cy5 excitation.

Treatment of cells with carbonyl cyanide m-chlorophenyl hydrazone. E. coli MG1655 cells from an overnight culture in MOPS supplemented with $0.4 \%$ (w/v) glucose (MOPS-G) were diluted into the same medium. Cells were grown for $2 \mathrm{~h}$ at $37{ }^{\circ} \mathrm{C}$ with or without $30 \mu \mathrm{M}$ carbonyl cyanide mchlorophenyl hydrazone (CCCP). The number of live cells at the time of CCCP addition were estimated as $5 \times 10^{7}$ c.f.u./mL. After a 4.5 -h incubation at $37{ }^{\circ} \mathrm{C}$ with neomycin or Neo-Cy5, cell survival was measured in c.f.u. $/ \mathrm{mL}$.

Neo-Cy5 uptake. For the liquid culture, MOPS-G was used. Overnight cultures were diluted to an $\mathrm{OD}_{600}$ of 0.037 with fresh medium and grown until the $\mathrm{OD}_{600}$ reached 0.2. Typically, $0.5 \mu \mathrm{L}$ of Neo-Cy5 dissolved in milliQ water was added to $5 \mu \mathrm{L}$ of the cell suspension (diluted 10 times). Cells were incubated in a heat block at $37{ }^{\circ} \mathrm{C}$ without shaking. To remove Neo-Cy5 not tightly bound or internalized, the samples were filtered through $0.45 \mu \mathrm{m}$-pore-size HAWP mixed cellulose ester (MCE) membranes (Merck Millipore) mounted on a micro-sample filtration Minifold II (Schleicher \& Schuell) and washed three times with $100 \mu \mathrm{L}$ MOPS-G prewarmed to $37{ }^{\circ} \mathrm{C}$. Immediately after filtration, the section of the membrane containing cells was placed into an Eppendorf tube containing MOPS-G, and cells were recovered by gentle up and down pipetting. Cells were immediately placed on $1 \%$ agarose pad for imaging by fluorescence microscopy or analysis by FACS.

Fluorescence microscopy. Fluorescence images were taken with an EMCCD camera (Photometrics) through a 63X total internal reflection fluorescence (TIRF) objective (Zeiss, NA 1.43) mounted on an inverted Zeiss Axio Observer Z1 microscope. Image acquisition was done with the Metamorph software package (Molecular Devices). Cy5 illumination was performed using a $642-\mathrm{nm}$ laser $\left(0.002 \mathrm{~kW} / \mathrm{cm}^{2}\right.$, Roper Scientific), and a filter set was used for fluorescence excitation and emission (Chroma Technology; ET 532/640 nm Laser Dual Band; excitation filter $530 / 20 \mathrm{~nm}$ and $638 / 25 \mathrm{~nm}$, dichroic mirror 585/70 nm and $650 \mathrm{~nm}$ (long pass), and emission filter $580 / 70 \mathrm{~nm}$ and 700/100 nm). Neo-Cy5 uptake was typically observed with an electron-multiplying gain of 1 or 50 and an exposure of 10 to $100 \mathrm{~ms}$. Spinach aptamer bound to 3,5-difluoro-4-hydroxybenzylidene imidazolinone was excited with a mercury lamp (excitation $470 \pm 20 \mathrm{~nm}$, emission $525 \pm 25 \mathrm{~nm}$ ). Image analyses were performed using Image J and microbeJ. ${ }^{68}$

FACS analysis. To measure Cy5 fluorescence, cells were analyzed with a BD Accuri C6 flow cytometer (BD Biosciences). For each experiment, more than 100000 events were recorded. Excitation was performed with a 640-nm diode laser $(14.7 \mathrm{~mW})$, and emission was detected through a $675 / 25 \mathrm{~nm}$ band pass filter. Data were analyzed with Kaluza 2.1 (Beckman Coulter) and FlowLogic 7.2. Binding affinity experiments were analyzed with the software GraphPad Prism 8.2.1. Data were fitted to a simple saturation curve.

\section{ASSOCIATED CONTENT}

\section{Supporting Information}

The Supporting Information is available free of charge on the ACS Publications website.

Supporting methods, 14 figures and one table showing additional results (PDF).

\section{AUTHOR INFORMATION}

\section{Corresponding Author}


* E-mail: dominique.fourmy@i2bc.paris-saclay.fr.

\section{Present Addresses}

$\dagger$ Institute for Environmental and Gender-Specific Medicine, Juntendo University Graduate School of Medicine, Chiba 2790021, Japan.

\section{Author Contributions}

S.Y. and D.F. designed the research strategy. M.S.A., M.O. and D.F performed the microscopy. M.S.A. performed the survival assays. M.S.A. and D.F performed the FACS and M.R. helped with analysis. M.O, S.Y. and D.F. performed the biochemistry. M.C. measured MIC in rich medium on Gram positive and negative strains and in minimal medium on pathogenic strains. M.S.A., M.O. and S. Y. performed other MIC experiments. D.F. performed the chemical synthesis and M.P.H. the NMR and LCMS. D.F. wrote the manuscript. All authors have given approval to the final version of the manuscript.

\section{ACKNOWLEDGMENTS}

We wish to thank Marc Mirande, Soufian Ouchane, Anne-Soisig Steunou, J. Dubois, Stéphanie Bury-Moné for use of equipment. We wish to thank David Buisson for help with the LC-MS. We wish to thank Christophe Beloin, Suzana Salcedo, Frédéric Boccard, Viginia Lioy, Etienne Dervyn, Jean-Luc Pernodet, Philippe Bouloc for strains and Isabelle Broutin for helpful discussions. The authors dedicate this paper to the memory of their colleague Jean-Louis Fourrey. This work was supported by the Centre National de la Recherche Scientifique (CNRS) to D.F. and S.Y. M.O. was supported by JASSO, a fellowship from the French embassy in Japan "Bourse du gouvernement français" and a fellowship from FRM (Fondation pour la recherche Médicale-FDT20140931068). M.S.A. was supported by a PhD fellowship from the French Ministère de l'Enseignement Supérieur et de la Recherche (MESR).

\section{REFERENCES}

(1) Jackson, J.; Chen, C.; Buising, K. Aminoglycosides: How Should We Use Them in the 21st Century? Curr. Opin. Infect. Dis. 2013, 26 (6), 516-525.

(2) Takahashi, Y.; Igarashi, M. Destination of Aminoglycoside Antibiotics in the "Post-Antibiotic Era." J. Antibiot. 2018, 71, 4-14.

(3) Aggen, J. B.; Armstrong, E. S.; Goldblum, A. A.; Dozzo, P.; Linsell, M. S.; Gliedt, M. J.; Hildebrandt, D. J.; Feeney, L. A.; Kubo, A.; Matias, R. D.; Lopez, S.; Gomez, M.; Wlasichuk, K. B.; Diokno, R.; Miller, G. H.; Moser, H. E. Synthesis and Spectrum of the Neoglycoside ACHN-490. Antimicrob. Agents Chemother. 2010, 54 (11), 4636-4642.

(4) Huth, M. E.; Han, K.-H.; Sotoudeh, K.; Hsieh, Y.-J.; Effertz, T.; Vu, A. A.; Verhoeven, S.; Hsieh, M. H.; Greenhouse, R.; Cheng, A. G.; Ricci, A. J. Designer Aminoglycosides Prevent Cochlear Hair Cell Loss and Hearing Loss. J. Clin. Invest. 2015, 125 (2), 583-592.

(5) Matt, T.; Ng, C. L.; Lang, K.; Sha, S.-H.; Akbergenov, R.; Shcherbakov, D.; Meyer, M.; Duscha, S.; Xie, J.; Dubbaka, S. R.; Perez-Fernandez, D.; Vasella, A.; Ramakrishnan, V.; Schacht, J.; Böttger, E. C. Dissociation of Antibacterial Activity and Aminoglycoside Ototoxicity in the 4-Monosubstituted 2Deoxystreptamine Apramycin. Proc. Natl. Acad. Sci. U.S.A.
2012, 109 (27), 10984-10989.

(6) Sato, R.; Tanigawara, Y.; Kaku, M.; Aikawa, N.; Shimizu, K. Pharmacokinetic-Pharmacodynamic Relationship of Arbekacin for Treatment of Patients Infected with Methicillin-Resistant Staphylococcus Aureus. Antimicrob. Agents Chemother. 2006, 50 (11), 3763-3769.

(7) Zhanel, G. G.; Lawson, C. D.; Zelenitsky, S.; Findlay, B.; Schweizer, F.; Adam, H.; Walkty, A.; Rubinstein, E.; Gin, A. S.; Hoban, D. J.; Lynch, J. P.; Karlowsky, J. A. Comparison of the Next-Generation Aminoglycoside Plazomicin to Gentamicin, Tobramycin and Amikacin. Expert Rev Anti Infect Ther 2012, $10(4), 459-473$.

(8) Borovinskaya, M. A.; Pai, R. D.; Zhang, W.; Schuwirth, B. S.; Holton, J. M.; Hirokawa, G.; Kaji, H.; Kaji, A.; Cate, J. H. Structural Basis for Aminoglycoside Inhibition of Bacterial Ribosome Recycling. Nat Struct Mol Biol 2007, 14 (8), $727-$ 732.

(9) Campuzano, S.; Vazquez, D.; Modolell, J. Functional Interaction of Neomycin B and Related Antibiotics with 30 S and 50S Ribosomal Subunits. Biochem Biophys Res Commun 1979, 87 (3), 960-966.

(10) Moazed, D.; Noller, H. F. Interaction of Antibiotics with Functional Sites in 16S Ribosomal RNA. Nature 1987, 327 (6121), 389-394.

(11) Davies, J.; Gorini, L.; Davis, B. D. Misreading of RNA Codewords Induced by Aminoglycoside Antibiotics. Mol Pharmacol 1965, 1 (1), 93-106.

(12) Carter, A. P.; Clemons, W. M.; Brodersen, D. E.; MorganWarren, R. J.; Wimberly, B. T.; Ramakrishnan, V. Functional Insights from the Structure of the 30S Ribosomal Subunit and Its Interactions with Antibiotics. Nature 2000, 407 (6802), 340 348.

(13) Demeshkina, N.; Jenner, L.; Westhof, E.; Yusupov, M.; Yusupova, G. A New Understanding of the Decoding Principle on the Ribosome. Nature 2012, 484 (7393), 256-259.

(14) Fourmy, D.; Recht, M. I.; Blanchard, S. C.; Puglisi, J. D. Structure of the A Site of Escherichia Coli 16S Ribosomal RNA Complexed with an Aminoglycoside Antibiotic. Science 1996, 274 (5291), 1367-1371.

(15) Vicens, Q.; Westhof, E. Crystal Structure of Paromomycin Docked into the Eubacterial Ribosomal Decoding A Site. Structure 2001, 9 (8), 647-658.

(16) Yoshizawa, S.; Fourmy, D.; Puglisi, J. D. Structural Origins of Gentamicin Antibiotic Action. Embo J 1998, 17 (22), 6437 6448

(17) Cabanas, M. J.; Vazquez, D.; Modolell, J. Inhibition of Ribosomal Translocation by Aminoglycoside Antibiotics. Biochem Biophys Res Commun 1978, 83 (3), 991-997.

(18) Misumi, M.; Nishimura, T.; Komai, T.; Tanaka, N. Interaction of Kanamycin and Related Antibiotics with the Large Subunit of Ribosomes and the Inhibition of Translocation. Biochem Biophys Res Commun 1978, 84 (2), 358-365.

(19) Hirokawa, G.; Kiel, M. C.; Muto, A.; Selmer, M.; Raj, V. 
S.; Liljas, A.; Igarashi, K.; Kaji, H.; Kaji, A. Post-Termination Complex Disassembly by Ribosome Recycling Factor, a Functional TRNA Mimic. Embo J 2002, 21 (9), 2272-2281.

(20) Hirokawa, G.; Kaji, H.; Kaji, A. Inhibition of Antiassociation Activity of Translation Initiation Factor 3 by Paromomycin. Antimicrob Agents Chemother 2007, 51 (1), 175-180.

(21) Wallace, B. J.; Tai, P. C.; Herzog, E. L.; Davis, B. D. Partial Inhibition of Polysomal Ribosomes of Escherichia Coli by Streptomycin. Proc Natl Acad Sci U S A 1973, 70 (4), 12341237.

(22) Foster, C.; Champney, W. S. Characterization of a $30 \mathrm{~S}$ Ribosomal Subunit Assembly Intermediate Found in Escherichia Coli Cells Growing with Neomycin or Paromomycin. Arch Microbiol 2008, 189 (5), 441-449.

(23) Mehta, R.; Champney, W. S. 30S Ribosomal Subunit Assembly Is a Target for Inhibition by Aminoglycosides in Escherichia Coli. Antimicrob Agents Chemother 2002, 46 (5), 15461549

(24) Sykes, M. T.; Shajani, Z.; Sperling, E.; Beck, A. H.; Williamson, J. R. Quantitative Proteomic Analysis of Ribosome Assembly and Turnover in Vivo. J Mol Biol 2010, 403 (3), 331345 .

(25) Davis, B. D. Mechanism of Bactericidal Action of Aminoglycosides. Microbiol Rev 1987, 51 (3), 341-350.

(26) Hancock, R. E. Aminoglycoside Uptake and Mode of Action-with Special Reference to Streptomycin and Gentamicin. II. Effects of Aminoglycosides on Cells. J. Antimicrob. Chemother. 1981, 8 (6), 429-445.

(27) Taber, H. W.; Mueller, J. P.; Miller, P. F.; Arrow, A. S. Bacterial Uptake of Aminoglycoside Antibiotics. Microbiol Rev 1987, 51 (4), 439-457.

(28) Bryan, L. E.; Kwan, S. Mechanisms of Aminoglycoside Resistance of Anaerobic Bacteria and Facultative Bacteria Grown Anaerobically. J. Antimicrob. Chemother. 1981, 8 Suppl $D, 1-8$.

(29) Damper, P. D.; Epstein, W. Role of the Membrane Potential in Bacterial Resistance to Aminoglycoside Antibiotics. Antimicrob. Agents Chemother. 1981, 20 (6), 803-808.

(30) Eisenberg, E. S.; Mandel, L. J.; Kaback, H. R.; Miller, M. H. Quantitative Association between Electrical Potential across the Cytoplasmic Membrane and Early Gentamicin Uptake and Killing in Staphylococcus Aureus. J. Bacteriol. 1984, 157 (3), $863-867$

(31) Davis, B. D.; Chen, L. L.; Tai, P. C. Misread Protein Creates Membrane Channels: An Essential Step in the Bactericidal Action of Aminoglycosides. Proc Natl Acad Sci U S A 1986, 83 (16), 6164-6168.

(32) Hancock, R. E. Aminoglycoside Uptake and Mode of Action with Special Reference to Streptomycin and Gentamicin. I. Antagonists and Mutants. J. Antimicrob. Chemother. 1981, 8 (4), 249-276.

(33) Peng, B.; Su, Y.-B.; Li, H.; Han, Y.; Guo, C.; Tian, Y.-M.; Peng, X.-X. Exogenous Alanine and/or Glucose plus Kanamy- cin Kills Antibiotic-Resistant Bacteria. Cell Metab. 2015, 21 (2), 249-262.

(34) Stone, M. R. L.; Butler, M. S.; Phetsang, W.; Cooper, M. A.; Blaskovich, M. A. T. Fluorescent Antibiotics: New Research Tools to Fight Antibiotic Resistance. Trends Biotechnol. 2018, $36(5), 523-536$.

(35) Allison, K. R.; Brynildsen, M. P.; Collins, J. J. MetaboliteEnabled Eradication of Bacterial Persisters by Aminoglycosides. Nature 2011, 473 (7346), 216-220

(36) Cinquin, B.; Maigre, L.; Pinet, E.; Chevalier, J.; Stavenger, R. A.; Mills, S.; Réfrégiers, M.; Pagès, J.-M. Microspectrometric Insights on the Uptake of Antibiotics at the Single Bacterial Cell Level. Sci Rep 2015, 5, 17968.

(37) Vergalli, J.; Dumont, E.; Pajović, J.; Cinquin, B.; Maigre, L.; Masi, M.; Réfrégiers, M.; Pagés, J.-M. Spectrofluorimetric Quantification of Antibiotic Drug Concentration in Bacterial Cells for the Characterization of Translocation across Bacterial Membranes. Nat Protoc 2018, 13 (6), 1348-1361.

(38) Dumont, E.; Vergalli, J.; Conraux, L.; Taillier, C.; Vassort, A.; Pajovic, J.; Réfrégiers, M.; Mourez, M.; Pagès, J.-M. Antibiotics and Efflux: Combined Spectrofluorimetry and Mass Spectrometry to Evaluate the Involvement of Concentration and Efflux Activity in Antibiotic Intracellular Accumulation. $J$. Antimicrob. Chemother. 2019, 74 (1), 58-65.

(39) Hernandez Linares, A.; Fourmy, D.; Fourrey, J.-L.; Loukaci, A. Introduction of a Substituent at the 5"-Position of N-Boc Neomycin B under Mitsunobu Reaction Conditions. Org. Biomol. Chem. 2005, 3 (11), 2064-2066.

(40) Dempsey, G. T.; Vaughan, J. C.; Chen, K. H.; Bates, M.; Zhuang, X. Evaluation of Fluorophores for Optimal Performance in Localization-Based Super-Resolution Imaging. Nat Methods 2011, 8 (12), 1027-1036.

(41) Recht, M. I.; Douthwaite, S.; Puglisi, J. D. Basis for Prokaryotic Specificity of Action of Aminoglycoside Antibiotics. Embo J 1999, 18 (11), 3133-3138.

(42) Pfister, P.; Hobbie, S.; Brull, C.; Corti, N.; Vasella, A.; Westhof, E.; Bottger, E. C. Mutagenesis of 16S RRNA C1409G1491 Base-Pair Differentiates between 6'OH and 6'NH3+ Aminoglycosides. J Mol Biol 2005, 346 (2), 467-475.

(43) Perez-Fernandez, D.; Shcherbakov, D.; Matt, T.; Leong, N. C.; Kudyba, I.; Duscha, S.; Boukari, H.; Patak, R.; Dubbaka, S. R.; Lang, K.; Meyer, M.; Akbergenov, R.; Freihofer, P.; Vaddi, S.; Thommes, P.; Ramakrishnan, V.; Vasella, A.; Böttger, E. C. 4'-O-Substitutions Determine Selectivity of Aminoglycoside Antibiotics. Nat Commun 2014, 5, 3112.

(44) Perzynski, S.; Cannon, M.; Cundliffe, E.; Chahwala, S. B.; Davies, J. Effects of Apramycin, a Novel Aminoglycoside Antibiotic on Bacterial Protein Synthesis. Eur. J. Biochem. 1979, 99 (3), 623-628.

(45) Hancock, R. E.; Farmer, S. W.; Li, Z. S.; Poole, K. Interaction of Aminoglycosides with the Outer Membranes and Purified Lipopolysaccharide and OmpF Porin of Escherichia Coli. Antimicrob Agents Chemother 1991, 35 (7), 1309-1314.

(46) Okuda, M.; Fourmy, D.; Yoshizawa, S. Use of Baby Spin- 
ach and Broccoli for Imaging of Structured Cellular RNAs. Nucleic Acids Res. 2017, 45 (3), 1404-1415.

(47) Jörgensen, F.; Kurland, C. G. Death Rates of Bacterial Mutants. FEMS Microbiology Letters 1987, 40 (1), 43-46.

(48) White, J. R.; White, H. L. Streptomycinoid Antibiotics: Synergism by Puromycin. Science 1964, 146 (3645), 772-774.

(49) Klainer, A. S.; Russell, R. R. Effect of the Inhibition of Protein Synthesis on the Escherichia Coli Cell Envelope. Antimicrob. Agents Chemother. 1974, 6 (2), 216-224.

(50) Ezraty, B.; Vergnes, A.; Banzhaf, M.; Duverger, Y.; Huguenot, A.; Brochado, A. R.; Su, S. Y.; Espinosa, L.; Loiseau, L.; Py, B.; Typas, A.; Barras, F. Fe-S Cluster Biosynthesis Controls Uptake of Aminoglycosides in a ROS-Less Death Pathway. Science 2013, 340 (6140), 1583-1587.

(51) Bryan, L. E.; Elzen, H. M. V. D. Streptomycin Accumulation in Susceptible and Resistant Strains of Escherichia Coli and Pseudomonas Aeruginosa. Antimicrob. Agents Chemother. 1976, 9 (6), 928-938.

(52) Aires, J. R.; Köhler, T.; Nikaido, H.; Plésiat, P. Involvement of an Active Efflux System in the Natural Resistance of Pseudomonas Aeruginosa to Aminoglycosides. Antimicrob. Agents Chemother. 1999, 43 (11), 2624-2628.

(53) Sobel, M. L.; McKay, G. A.; Poole, K. Contribution of the MexXY Multidrug Transporter to Aminoglycoside Resistance in Pseudomonas Aeruginosa Clinical Isolates. Antimicrob. Agents Chemother. 2003, 47 (10), 3202-3207.

(54) Westbrock-Wadman, S.; Sherman, D. R.; Hickey, M. J.; Coulter, S. N.; Zhu, Y. Q.; Warrener, P.; Nguyen, L. Y.; Shawar, R. M.; Folger, K. R.; Stover, C. K. Characterization of a Pseudomonas Aeruginosa Efflux Pump Contributing to Aminoglycoside Impermeability. Antimicrob. Agents Chemother. 1999, 43 (12), 2975-2983.

(55) Li, X.-Z.; Nikaido, H. Efflux-Mediated Drug Resistance in Bacteria. Drugs 2004, 64 (2), 159-204.

(56) Monlezun, L.; Phan, G.; Benabdelhak, H.; Lascombe, M.B.; Enguéné, V. Y. N.; Picard, M.; Broutin, I. New OprM Structure Highlighting the Nature of the N-Terminal Anchor. Front Microbiol 2015, 6, 667.

(57) Nakashima, R.; Sakurai, K.; Yamasaki, S.; Nishino, K.; Yamaguchi, A. Structures of the Multidrug Exporter AcrB Reveal a Proximal Multisite Drug-Binding Pocket. Nature 2011, 480 (7378), 565-569.
(58) Murakami, S.; Nakashima, R.; Yamashita, E.; Matsumoto, T.; Yamaguchi, A. Crystal Structures of a Multidrug Transporter Reveal a Functionally Rotating Mechanism. Nature 2006, 443 (7108), 173-179.

(59) Hadidi, K.; Wexselblatt, E.; Esko, J. D.; Tor, Y. Cellular Uptake of Modified Aminoglycosides. J. Antibiot. 2018, 71, $142-145$

(60) Böttger, E. C.; Crich, D. Aminoglycosides: Time for the Resurrection of a Neglected Class of Antibacterials? ACS Infect Dis 2020, 6 (2), 168-172.

(61) Sati, G. C.; Sarpe, V. A.; Furukawa, T.; Mondal, S.; Mantovani, M.; Hobbie, S. N.; Vasella, A.; Böttger, E. C.; Crich, D. Modification at the 2'-Position of the 4,5-Series of 2Deoxystreptamine Aminoglycoside Antibiotics To Resist Aminoglycoside Modifying Enzymes and Increase Ribosomal Target Selectivity. ACS Infect Dis 2019, 5 (10), 1718-1730.

(62) Jagt, R. B. C.; Gómez-Biagi, R. F.; Nitz, M. Pattern-Based Recognition of Heparin Contaminants by an Array of SelfAssembling Fluorescent Receptors. Angew. Chem. Int. Ed. Engl. 2009, 48 (11), 1995-1997.

(63) Mazauric, M. H.; Leroy, J. L.; Visscher, K.; Yoshizawa, S.; Fourmy, D. Footprinting Analysis of BWYV PseudoknotRibosome Complexes. Rna 2009, 15 (9), 1775-1786.

(64) Powers, T.; Noller, H. F. A Functional Pseudoknot in 16S Ribosomal RNA. Embo J 1991, 10 (8), 2203-2214.

(65) Yoshizawa, S.; Fourmy, D.; Puglisi, J. D. Recognition of the Codon-Anticodon Helix by Ribosomal RNA. Science 1999, 285 (5434), 1722-1725.

(66) Fourmy, D.; Yoshizawa, S. Protein-RNA Footprinting: An Evolving Tool. Wiley Interdiscip Rev RNA 2012, 3 (4), 557566.

(67) Ying, B. W.; Fourmy, D.; Yoshizawa, S. Substitution of the Use of Radioactivity by Fluorescence for Biochemical Studies of RNA. Rna 2007, 13 (11), 2042-2050.

(68) Ducret, A.; Quardokus, E. M.; Brun, Y. V. MicrobeJ, a Tool for High Throughput Bacterial Cell Detection and Quantitative Analysis. Nat Microbiol 2016, 1 (7), 16077. 


\section{For Table of Contents Only}

Fluorescent aminoglycoside antibiotics and methods for accurately monitoring uptake by bacteria

Mahnaz Sabeti Azad, Maho Okuda, Mélina Cyrenne, Mickael Bourge, Marie-Pierre Heck, Satoko Yoshizawa, and Dominique Fourmy.

brief synopsis, describing the graphic and explaining how the manuscript relates to sustainability:

Fluorescently labeled aminoglycoside derivatives with uptake and bactericidal activities similar to those of the parent drug were generated for facilitating studies involving aminoglycoside antibiotics. Robust characterization of the drug uptake is enabled by the method which combines fluorescence microscopy with fluorescence-activated cell sorting (FACS) using neomycin coupled to non-permeable cyanine dyes.

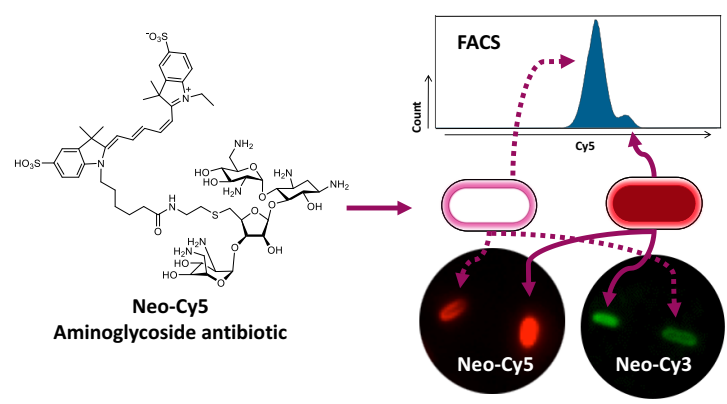




\section{Supporting Information}

Fluorescent aminoglycoside antibiotics and methods for accurately monitoring uptake by bacteria

Mahnaz Sabeti Azad ${ }^{\dagger}$, Maho Okuda ${ }^{\dagger, \ddagger}$, Mélina Cyrenne ${ }^{\dagger}$, Mickael Bourge ${ }^{\dagger}$, Marie-Pierre Heck§ $^{\S}$, Satoko Yoshizawa ${ }^{\dagger}$, and Dominique Fourmy*,†.

† Université Paris-Saclay, CEA, CNRS, Institute for Integrative Biology of the Cell (I2BC), 91198, Gif-sur-Yvette, France.

$\S$ Université Paris-Saclay, CEA, Service de Chimie Bio-organique et de Marquage, 91191 Gif-sur-Yvette, France.

Corresponding author

${ }^{*}$ E-mail : dominique.fourmy@i2bc.paris-saclay.fr

17 pages

Supporting methods

14 figures

1 tables: 


\section{Supporting methods}

Products were verified by ${ }^{1} \mathrm{H}$ and ${ }^{13} \mathrm{C}$ Nuclear Magnetic Resonance spectroscopy (NMR) or Liquid Chromatography Mass Spectrometry (LC-MS). NMR could not be performed for Neo-Cy5 as the quantities synthetized were too low.

\section{Synthetic Procedures and characterization data}

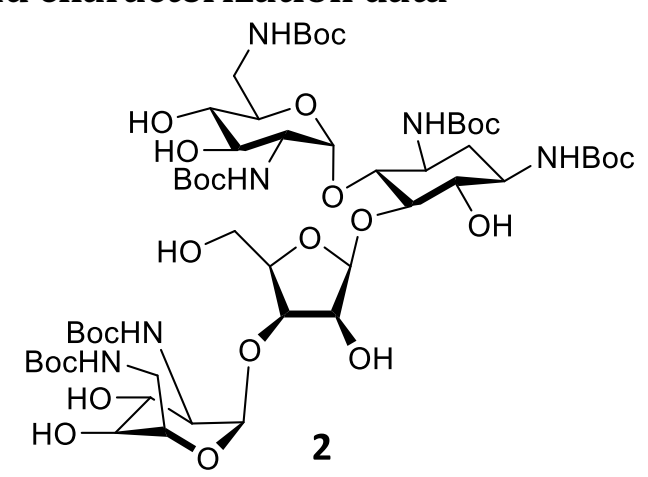

1,3,2',6',2'",6'" Hexa-N-tert-butyloxycarbonylneomycin 2: To a solution of commercially available Neomycin sulfate $(1 \mathrm{~g}, 1,4 \mathrm{mmol})$ in $\mathrm{DMF} / \mathrm{H}_{2} \mathrm{O}(20 \mathrm{~mL} / 20 \mathrm{~mL})$ were added triethylamine $(9 \mathrm{~mL})$ and di-tert-butyl dicarbonate $(2,1 \mathrm{~g}, 9,62 \mathrm{mmol}, 6.9$ eq.). The mixture was heated at $60^{\circ} \mathrm{C}$ for $5 \mathrm{~h}$. After concentration under vacuum, the crude was dissolved in EtOAc and washed with brine. The organic layer was recovered and dried on $\mathrm{MgSO}_{4}$. After concentration and purification of the crude by silicagel column chromatography $\left(\mathrm{CH}_{2} \mathrm{Cl}_{2} / \mathrm{MeOH}(9 / 1)\right) 2$ was isolated (876 mg, $52 \%$ yield; oil). ${ }^{1} \mathrm{H}$ NMR (300 MHz, CD $\mathrm{OD}$ ) $\delta=5.45$ (br, 1H, H1'), 5.25 (br, 1H, H1'), 5.10 (br, 1H, H1'"), 4.9-4.8 (m, 2H), 4.2-4.11 (br, $2 \mathrm{H}), 3.9(\mathrm{~m}, 1 \mathrm{H}), 3.85-3.78(\mathrm{~m}, 3 \mathrm{H}), 3.76-3.55(\mathrm{~m}, 5 \mathrm{H}), 3.52-$ $3.39(\mathrm{~m}, 6 \mathrm{H}), 3.32-3.22(\mathrm{~m}, 5 \mathrm{H}), 1.90(\mathrm{br}, 1 \mathrm{H}, \mathrm{Heq}), 1.49-1.35(\mathrm{~m}, 54 \mathrm{H}), 1.3$ (br, 1H, $\mathrm{Hax}) ;{ }^{13} \mathrm{C}$ NMR $\left(75 \mathrm{MHz}, \mathrm{CD}_{3} \mathrm{OD}\right) \delta=158.8,158.3,158.0,157.8 ; 110.5,100.2,99.2,87.6$, 83.3, 80.6, 78.2, 75.6, 74.3, 72.9, 72.4, 71.5, 69.0, 63.4, 57.1, 53.4, 52.2, 51.7, 42.6, 41.7, 35.8, 28.9. MS (ESI+): $\mathrm{m} / \mathrm{z}$ calculated for $\left[\mathrm{C}_{53} \mathrm{H}_{94} \mathrm{~N}_{6} \mathrm{O}_{25}+\mathrm{Na}\right]^{+}: 1237,6$, found : 1237,4; elemental Analysis calculated C, 52.38; $\mathrm{H}, 7.80 ; \mathrm{N}, 6.92 ; \mathrm{O}, 32.91$; found $\mathrm{C}, 49.95 ; \mathrm{H}, 7.91$; $\mathrm{N}, 6.55 ; 0,30.86$.

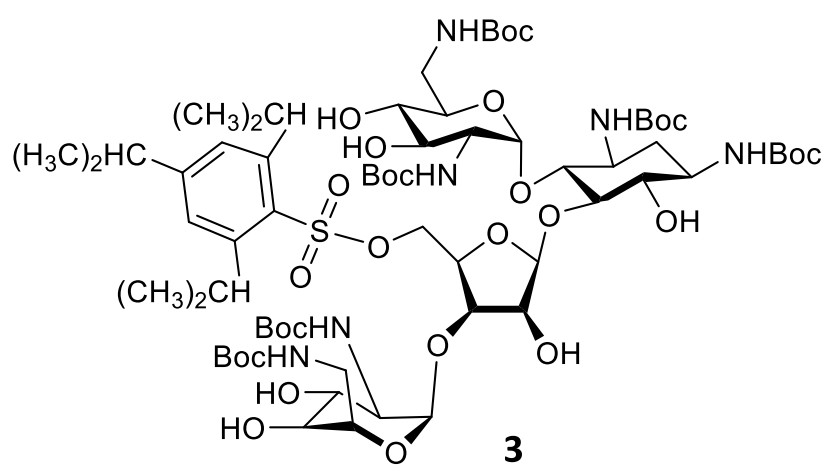

\section{5"-0-triisopropylbenzensulfonyl-1,3,2',6',2"',6"'-hexa-N-tert-butyloxycarbonyl}

Neomycin 3: To a solution of compound 2 (500 $\mathrm{mg}, 0.41 \mathrm{mmol})$ in pyridine (3 $\mathrm{mL})$ was added a solution of 2,4,6 triisopropylbenzenesulfonyl chloride $(4 \mathrm{~g})$ in pyridine $(7 \mathrm{~mL})$. The solution was stirred at RT for $48 \mathrm{~h}$ and was concentrated under vaccuum. The crude was dissolved in EtOAc and washed with brine. The organic layer was recovered, dried on $\mathrm{MgSO}_{4}$. After concentration and purification by silicagel column chromatography $\left(\mathrm{CH}_{2} \mathrm{Cl}_{2} / \mathrm{MeOH}(10 / 1)\right) 3$ was isolated (432 mg, $71 \%$ yield); ${ }^{1} \mathrm{H}$ NMR (300 MHz, $\mathrm{CD}_{3} \mathrm{OD}$ ) $\delta=7.01$ (s, 2H, Har), 6.1 (br, 1H, H1'), 5.18 (br, 1H, Heq), 4.9 (br, 1H, H1"'), 4.65-3.79 (m, 
8H), 4.3-4.0(m, 2H), 3.8-3.6 (m, 8H), 3.4-3.2 (m, 4H), 2.7 (br, 1H, Heq), 2.92-2.85 (m, 3H), 1.69 (br, 1H, Hax), 1.9-1.3 (m, 55H) . $1.18(\mathrm{~s}, 18 \mathrm{H}) ;{ }^{13} \mathrm{C}$ NMR (75 MHz, CD $\left.{ }_{3} \mathrm{OD}\right) \delta=169.5$, 159.4, 158.7, 158.5, 158.2, 157.7, 132.8, 132.4, 130.9, 130.2, 125.5, 111.1, 100.0, 98.6, 87.0, 81.1, 80.8, 80.7, 80.3, 79.2, 75.8, 74.8, 73.2, 72.8, 71.8, 71.2, 69.8, 69.4, 68.8, 68.5, $56.7,53.7,52.6,42.7,41.6,35.7,29.3,28.9,25.7,24.2,25.0 ;$ MS (ESI+): $\mathrm{m} / \mathrm{z}$ calculated for $\left[\mathrm{C}_{68} \mathrm{H}_{116} \mathrm{~N}_{6} \mathrm{O}_{27} \mathrm{~S}_{1}+\mathrm{Na}+\mathrm{H}\right]^{+}: 1504,7$; found: 1504.8, $\left[\mathrm{C}_{68} \mathrm{H}_{116} \mathrm{~N}_{6} \mathrm{O}_{27} \mathrm{~S}_{1}+2 \mathrm{Na}\right]^{2+}:$ 763.35, found : 763.5 .

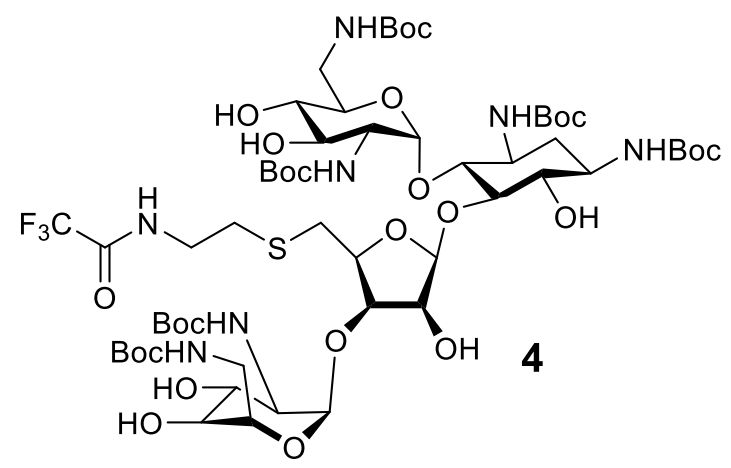

\section{5"-(2-N-trifluoroacetamidoethylthiol)-1,3,2',6',2"',6"'-Hexa-N-tert-}

butyloxycarbonyl-5"'-deoxyneomycin 4: To a solution of sodium ethoxide (4 mL, $3 \mathrm{M}$ in EtOH) under Argon was added commercially available 2,2,2-trifluoro-N-(2mercaptoethyl)acetamide (90 $\mathrm{mg}, 0.51 \mathrm{mmol})$ in EtOH (3 mL) and the mixture was stirred at RT for $15 \mathrm{~min}$. Then was added a solution of compound 3 ( $220 \mathrm{mg}, 0.15 \mathrm{mmol}$ ) in EtOH (3 mL) and the mixture was stirred at RT for 5 h. $20 \mathrm{~mL}$ of $\mathrm{CH}_{2} \mathrm{Cl}_{2}$ were added, and then an aqueous solution of sodium phosphate $(\mathrm{pH}=6)$. The organic layer was separated, dried on $\mathrm{MgSO}_{4}$ and concentrated. The crude was purified by silicagel column chromatography $\left(\mathrm{CH}_{2} \mathrm{Cl}_{2} / \mathrm{MeOH}(10 / 1)\right)$ to afford 4 (184 mg, $91 \%$ yield); ${ }^{1} \mathrm{H}$ NMR (300 $\left.\mathrm{MHz}, \mathrm{CD}_{3} \mathrm{OD}\right) \delta=6.75(\mathrm{~m}, 1 \mathrm{H}), 6.52(\mathrm{~m}, 2 \mathrm{H}), 6.15$ (br, 1H, H1'), 5.45 (br, 1H, H1"), 5.21 (br, 1H, H1"'), 4.8-4.3 (m, 6H), 4.28-4.15 (m, 2H), 4.08-4.0 (m, 1H), 3.8-3.75 (m, 2H), 3.72-3.63 (m, 2H), 3.59-3.45 (m, 6H), 3.39-3.22 (m, 4H), 2.81-2.79(m, 2H), 2.76-2.70 (m, $2 \mathrm{H}), 2.03-1.96(\mathrm{~m}, 1 \mathrm{H}, \mathrm{Heq}), 1.78-1.74(\mathrm{~m}, 1 \mathrm{H}), 1.52-1.48(\mathrm{~m}, 54 \mathrm{H}+\mathrm{Hax}) ; \mathrm{MS}$ (ESI-TOF): $\mathrm{m} / \mathrm{z}$ calculated for $\left[\mathrm{C}_{57} \mathrm{H}_{98} \mathrm{~F}_{3} \mathrm{~N}_{7} \mathrm{O}_{25} \mathrm{~S}_{1}+1 \mathrm{H}\right]^{+}: 1371,5$ found : 1371,5 $\left[\left[\mathrm{C}_{57} \mathrm{H}_{98} \mathrm{~F}_{3} \mathrm{~N}_{7} \mathrm{O}_{25} \mathrm{~S}_{1}+1 \mathrm{H}\right]^{2+}: 686.3\right.$, found : 686.4 .

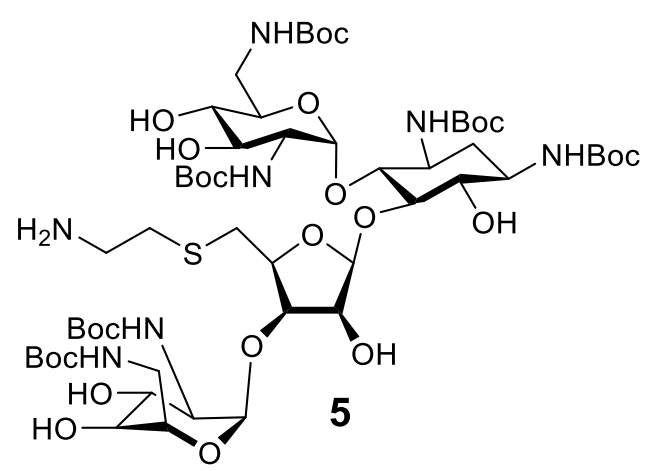

5"-(2-aminoethylthio-)-1,3,2',6',2"',6"'-Hexa-N-tert-butyloxycarbonyl-5"deoxyneomycin 5 :

Compound 4 (84 mg, $0.061 \mathrm{mmol}$ ) was dissolved in $\mathrm{NH}_{4} \mathrm{OH}$ solution in $\mathrm{MeOH}$ (3 mL, $70 \%)$. The solution was strirred at TA for $1 \mathrm{~h}$ and then concentrated under vaccum to 
afford 5 (36 mg, 46\% yield). ${ }^{1} \mathrm{H}$ NMR (300 MHz, $\left.\mathrm{CD}_{3} \mathrm{OD}\right) \delta=5.44$ (br, 1H, H1'), 5.2 (br, 1H, H1"'), 4.92 (br, 1H, H1"'), 1H), $4.34(\mathrm{~m}, 1 \mathrm{H}), 4.22(\mathrm{~m}, 1 \mathrm{H}), 4.05(\mathrm{~m}, 1 \mathrm{H}), 3.9(\mathrm{~m}, 2 \mathrm{H})$, 3.75(m, 2H), 3.64-3.12 (m, 15H), 3.0-2.78 (m, 4H), 1.95 (br, 1H, Heq), 1.68 (m, 1H, Hax), 1.64-1.38 (m, 54H); MS (ESI-TOF): $\mathrm{m} / \mathrm{z}$ calculated for $\left[\mathrm{C}_{55} \mathrm{H}_{99} \mathrm{~N}_{7} \mathrm{O}_{24} \mathrm{~S}_{1}+2 \mathrm{H}\right]^{+}: 1276,5$ found : 1276,06, [[ $\left.\mathrm{C}_{55} \mathrm{H}_{99} \mathrm{~N}_{7} \mathrm{O}_{24} \mathrm{~S}_{1}+2 \mathrm{H}:\right]^{2+}: 638.5$ found : 638.45 .

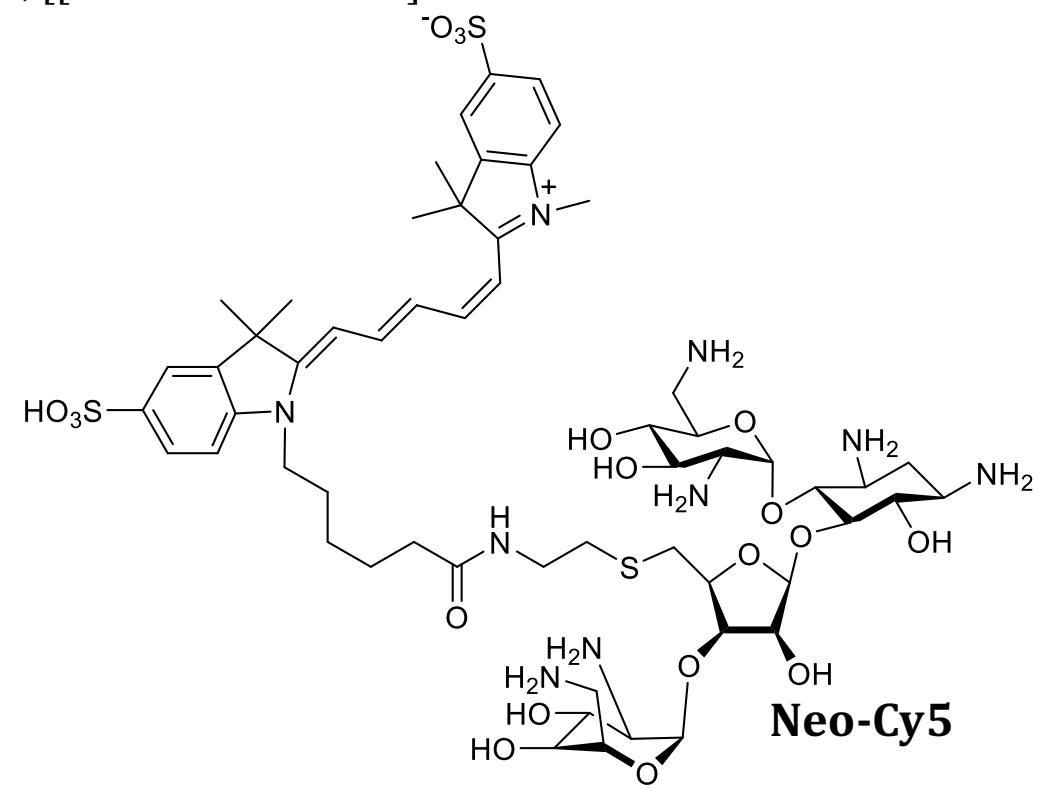

The compound 5 was resuspended in $100 \mu \mathrm{L}$ of dimethyl formamide (DMF). $\mathrm{N}, \mathrm{N}$ Diisopropylethylamine $(100 \mu \mathrm{L})$ was added to two micromoles of Cy5 (GE Healthcare) or Cyanine 5 (Lumiprobe) monofunctional NHS-ester previously dissolved in $500 \mu \mathrm{L}$ DMF. The sample was next placed for two hours at room temperature with the Bocneomycin derivative for coupling. The reaction was monitored by analytical thin-layer chromatography (TLC) on silica gel 60 F254 plates with eluant: chloroform/Ethanol/ $\mathrm{NH}_{4} \mathrm{OH}$ 5.6/3.8/0.45 (Figure S6c). Then the sample was dried under vacuum and kept at $-80^{\circ} \mathrm{C}$ if necessary. The product was dissolved in methanol for purification on TLC plates (Silica gel 60, Merck). The silica gel was recovered and placed in Eppendorf tubes and the product eluted in ethanol. The resin and the solvent were separated by centrifugation and the elution step repeated 3 times. The sample was dried and finally, removal of the butyloxycarbonyl groups was performed in trifluoroacetic acid (90\%) for 10 minutes at room temperature. 


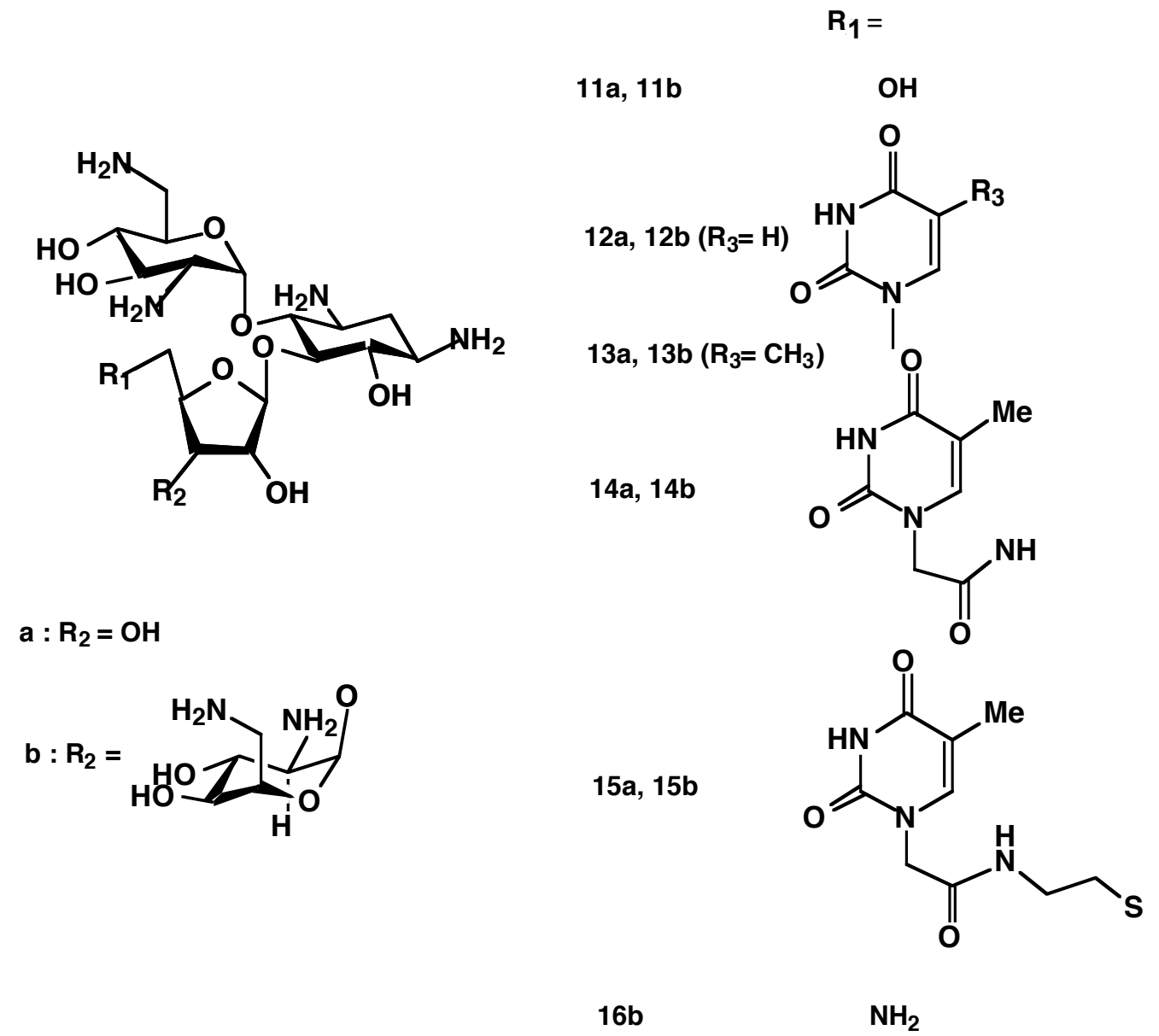

Figure S1. Derivatives of neomycin.

Table S1 : MIC values for neomycin derivatives against $E$. coli MG1655 cells grown in LB medium.

\begin{tabular}{|c|c|c|}
\hline product $\mathbf{N}^{\circ}$ & $\mathbf{R}_{\mathbf{1}}$ & $\mathbf{M I C} \boldsymbol{\mu g} / \mathbf{m l}$ \\
\hline $\mathbf{1 1 b}$ & $\mathrm{OH}$ & 5 \\
\hline $\mathbf{1 2 b}$ & uracil & 10 \\
\hline $\mathbf{1 3 b}$ & thymine & $>40$ \\
\hline $\mathbf{1 4 b}$ & thyminylacetyl & 20 \\
\hline $\mathbf{1 5 b}$ & thyminylacetamidoethylthio & 5 \\
\hline $\mathbf{1 6 b}$ & $\mathrm{NH}_{2}$ & $>40$ \\
\hline
\end{tabular}

Neomycin

Neo-U

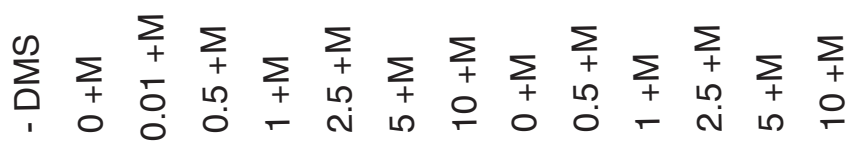

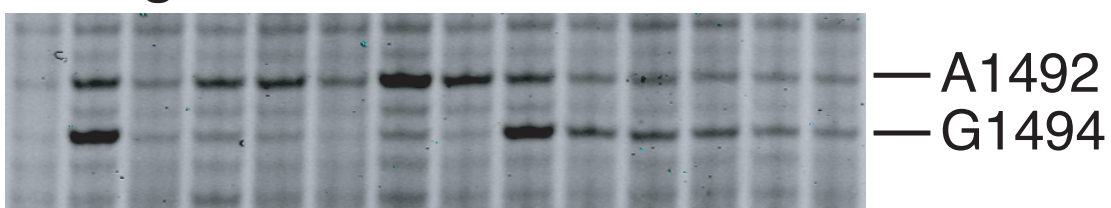


Figure S2. DMS probing of 30S ribosomal subunits bound to neomycin and Neo-U. The lane marked "- DMS" is a control reaction with no DMS added. Bands corresponding to nucleotides A1492 and G1494 are indicated.

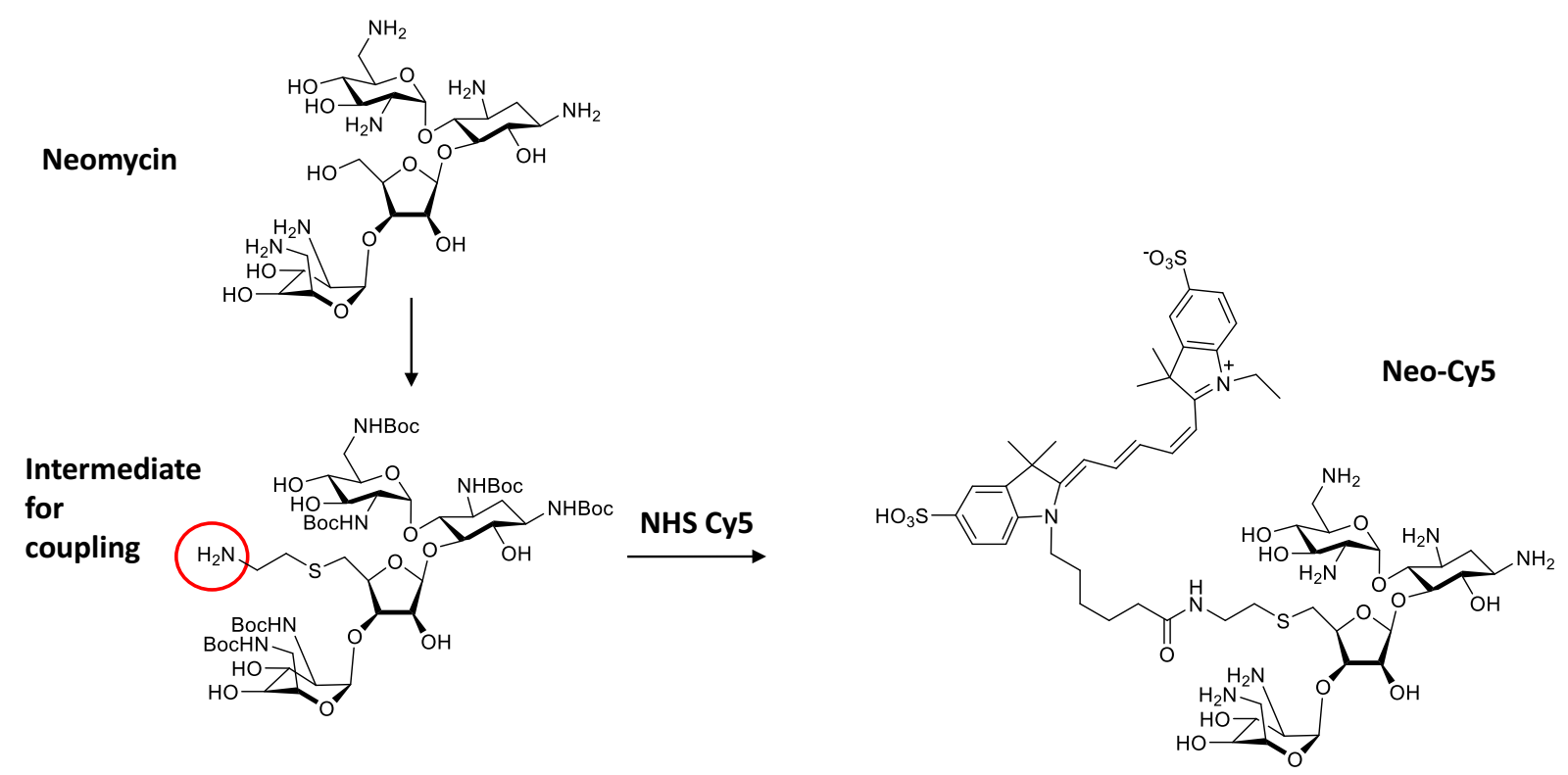

Figure S3. Scheme for generation of Neo-Cy5. The primary amine group that reacts with the NHS-ester-Cy5 is highlighted by the red circle. Other amino groups are protected by $\mathrm{N}$-tert-butyloxycarbonyl groups.
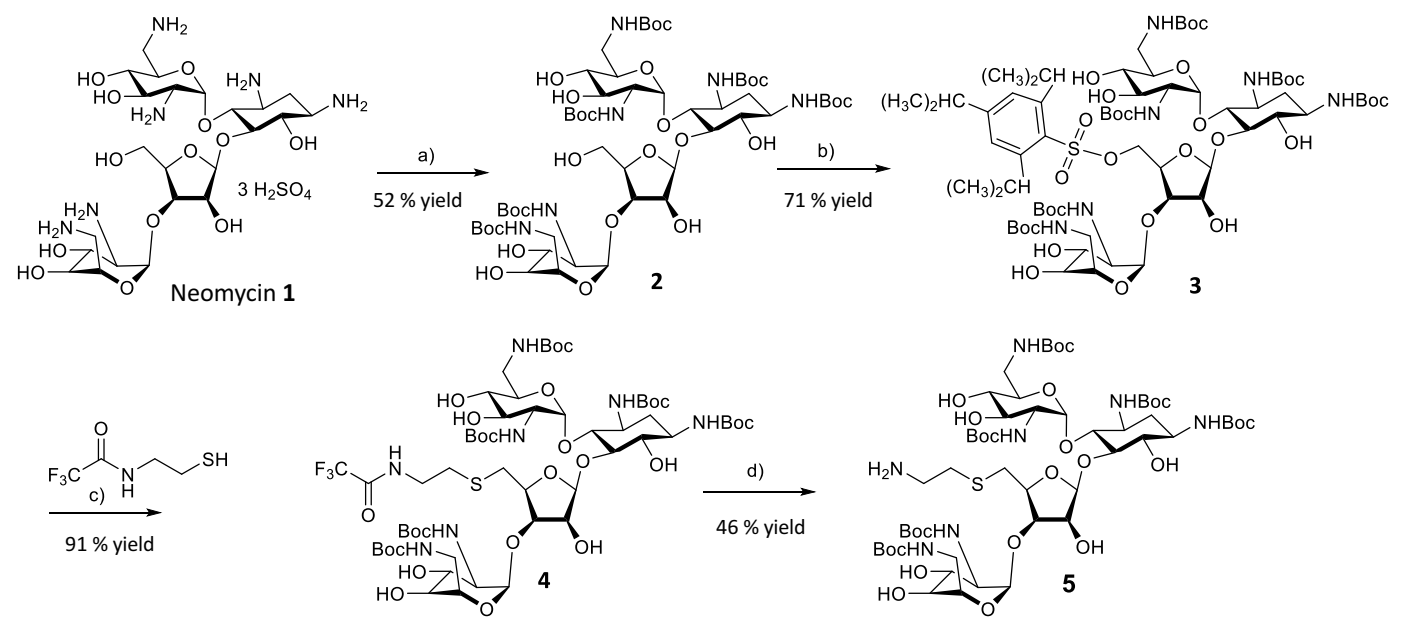

Conditions and reagents

a) TEA, Boc ${ }_{2} \mathrm{O}, \mathrm{DMF}, 60^{\circ} \mathrm{C} ; \mathrm{NH}_{4} \mathrm{OH}, \mathrm{MeOH}$; b) TIPBSCl, $\mathrm{Py}, \mathrm{RT} 48 \mathrm{~h}$; c) EtONa, trifluoro- $\mathrm{N}$-(2-mercaptoethyl)acetamide, $\mathrm{RT}, 5 \mathrm{~h}$; d) $\mathrm{NH}{ }_{4} \mathrm{OH}, \mathrm{MeOH}$

Figure S4. Synthesis of Boc-Neo-Cy5 from Boc-Neomycin. All steps were performed at room temperature. 


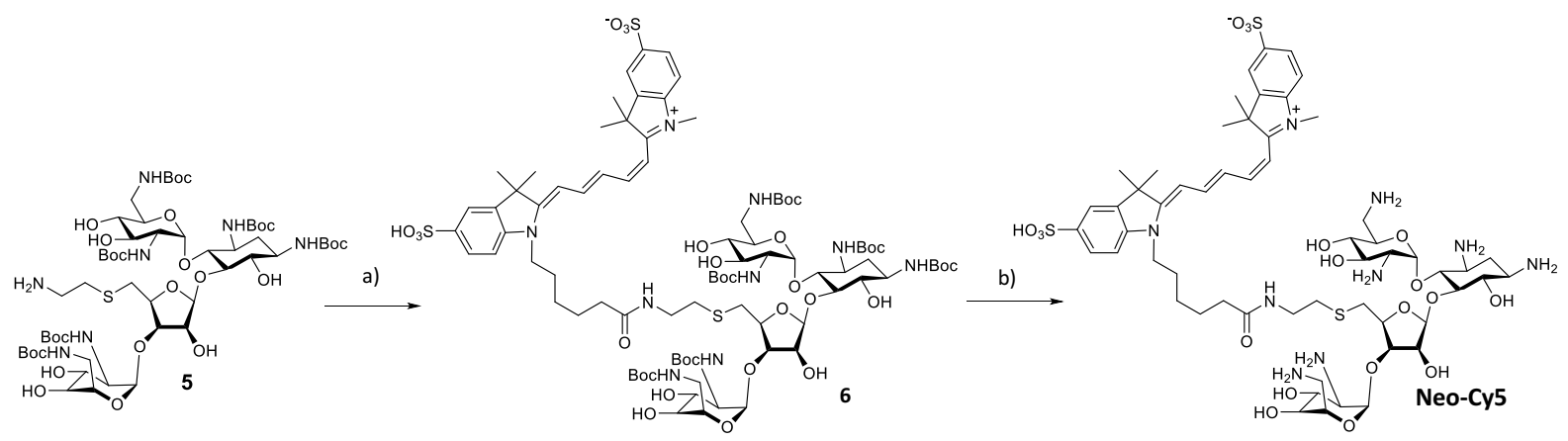

Conditions and reagents : a) $\mathrm{NH}_{4} \mathrm{OH}, \mathrm{MeOH}$, b) i) NHS-Cy5, DIEA, DMF; ii) TFA/ $\mathrm{H}_{2} \mathrm{O} 9 / 1$

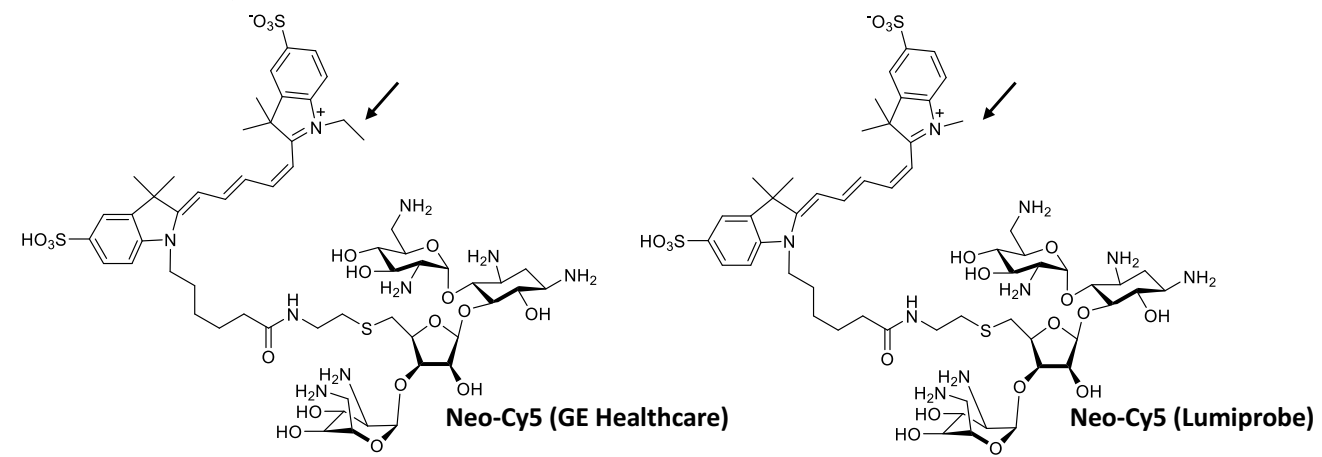

Figure S5. Synthesis of Boc-Neo-Cy5 from Boc-Neomycin. All steps were performed at room temperature. Below are indicated the two structures of Neo-Cy5 according to the source of Cy5-NHS (GE Healthcare or Lumiprobe). The difference is highlighted by an arrow. 
a)

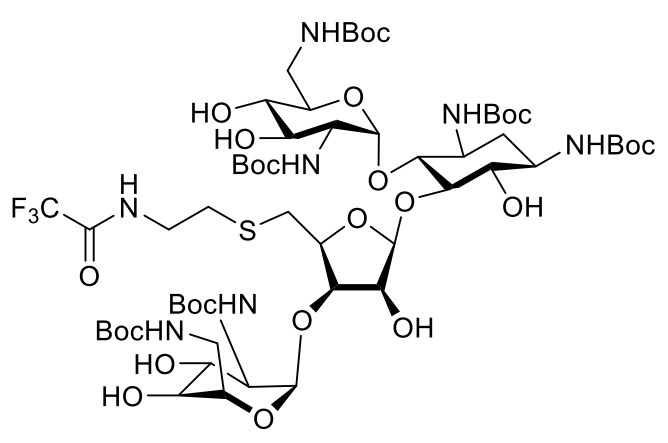

Chemical Formula: $\mathrm{C}_{57} \mathrm{H}_{98} \mathrm{~F}_{3} \mathrm{~N}_{7} \mathrm{O}_{25} \mathrm{~S}$

MS(ESI-TOF) $\mathrm{m} / \mathrm{z}$ calcd for $\left[\mathrm{C}_{57} \mathrm{H}_{98} \mathrm{~F}_{3} \mathrm{~N}_{7} \mathrm{O}_{25} \mathrm{~S}+1 \mathrm{H}\right]^{+}=1371,5$ found $=1371,5$

$\begin{array}{rr}\text { Peak ID Compound Time } & \text { Mass Found } \\ 53 & \text { Not Found }\end{array}$

53: (T1me: 3.56) Comb1ne (479:492-404:411)

1 . MS ES+

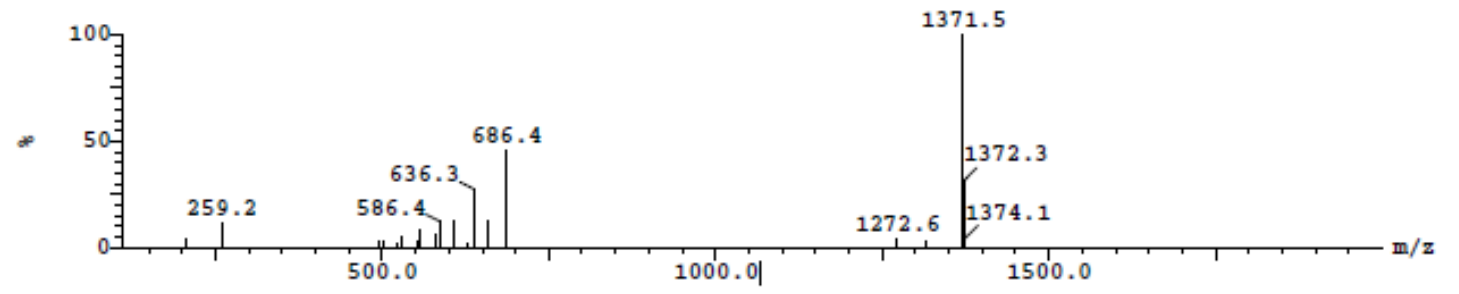


b)

MS obtained using an ESI-Quadripole autopurify (pump : 2545, mass: ZQ2000) mass spectrometer.

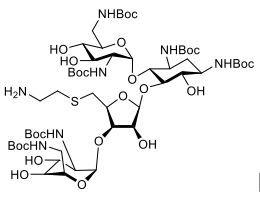

MS(ESI-TOF) $\mathrm{m} / \mathrm{z}$ calcd for $\left[\mathrm{C}_{55} \mathrm{H}_{99} \mathrm{~N}_{7} \mathrm{O}_{24} \mathrm{~S}_{1}+2 \mathrm{H}\right]^{+}=1276,5$, found $=1276,06$

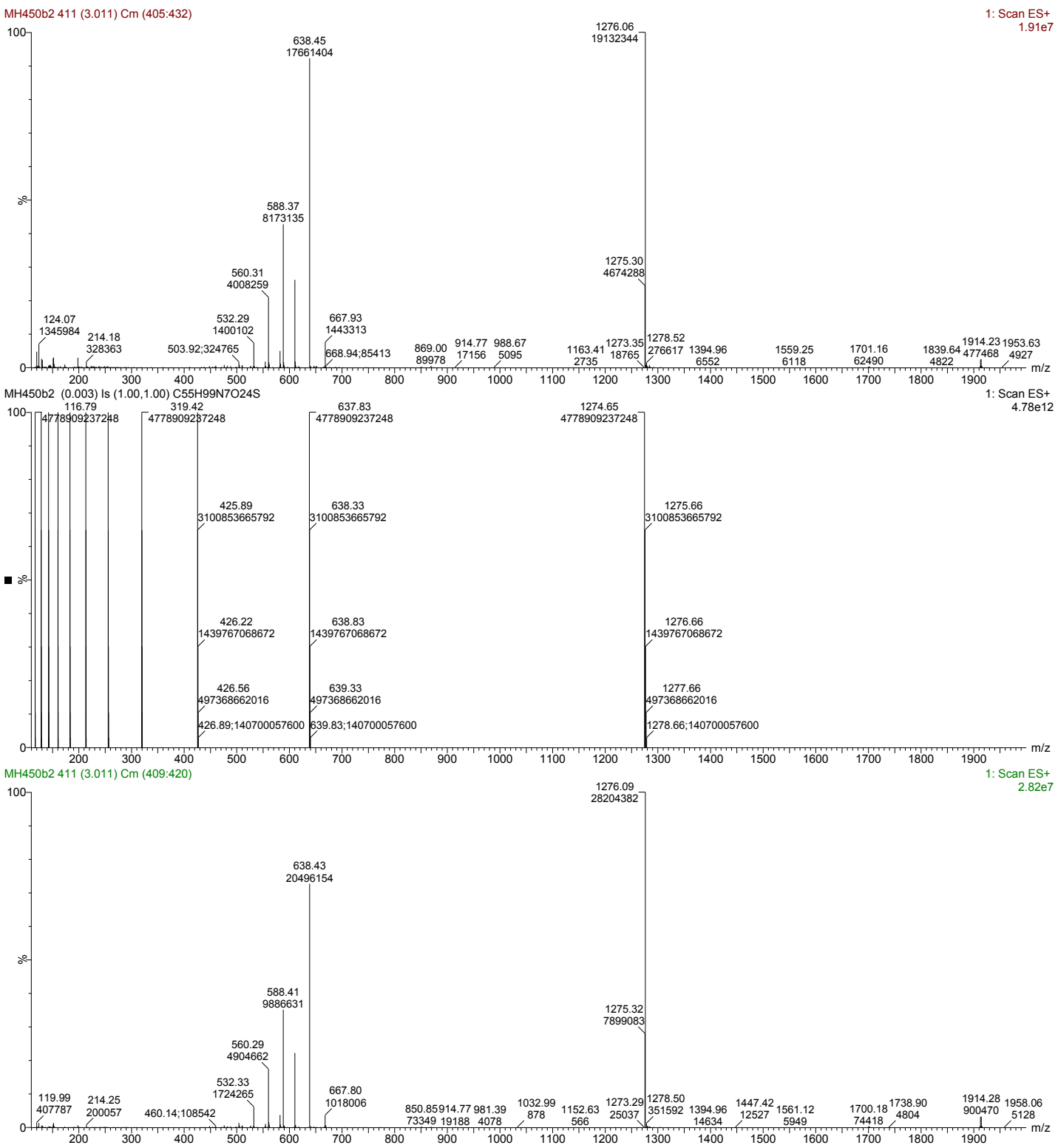


c)

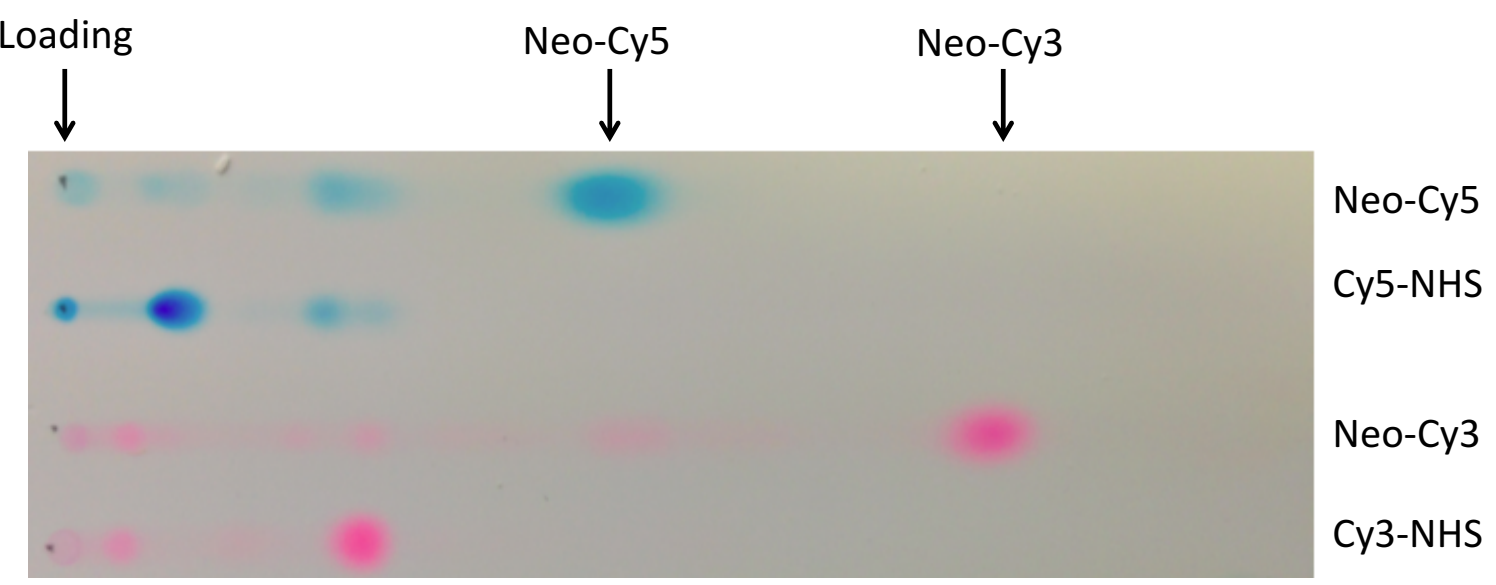

d)

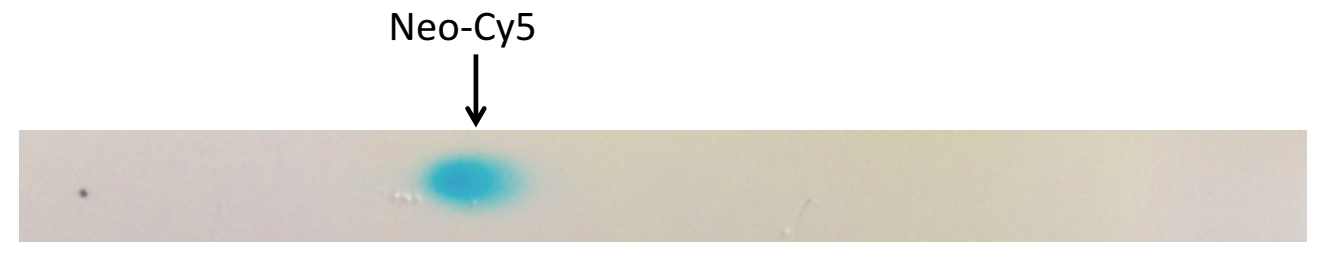

Neo-Cy5

e)

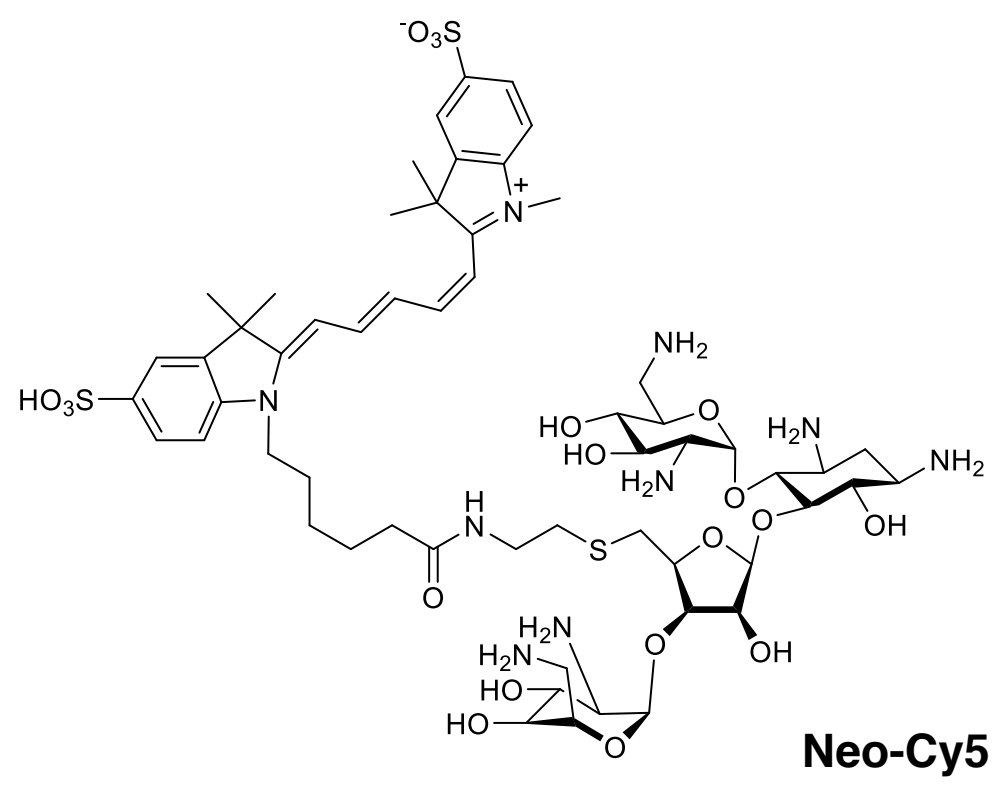

Chemical Formula: $\mathrm{C}_{57} \mathrm{H}_{87} \mathrm{~N}_{9} \mathrm{O}_{19} \mathrm{~S}_{3}{ }^{-}$

Exact Mass: 1297,53

Molecular Weight: 1298,55

MS obtained using an ESI-Quadripole autopurify (pump : 2545, mass: ZQ2000) mass spectrometer.

MS(ESI-TOF) $\mathrm{m} / \mathrm{z}$ calcd for $\left[\mathrm{C}_{57} \mathrm{H}_{87} \mathrm{~N}_{9} \mathrm{O}_{19} \mathrm{~S}_{3}-1 \mathrm{H}\right]^{-}=1297,54$, found $=1297,56 ;\left[\mathrm{C}_{57} \mathrm{H}_{87} \mathrm{~N}_{9} \mathrm{O}_{19} \mathrm{~S}_{3}-2 \mathrm{H}\right]^{2-}=$ 648.75 , found $=648,37 ;\left[\mathrm{C}_{57} \mathrm{H}_{87} \mathrm{~N}_{9} \mathrm{O}_{19} \mathrm{~S}_{3}+3 \mathrm{H}\right]^{3+}=433,67$, found $=434,01$. 


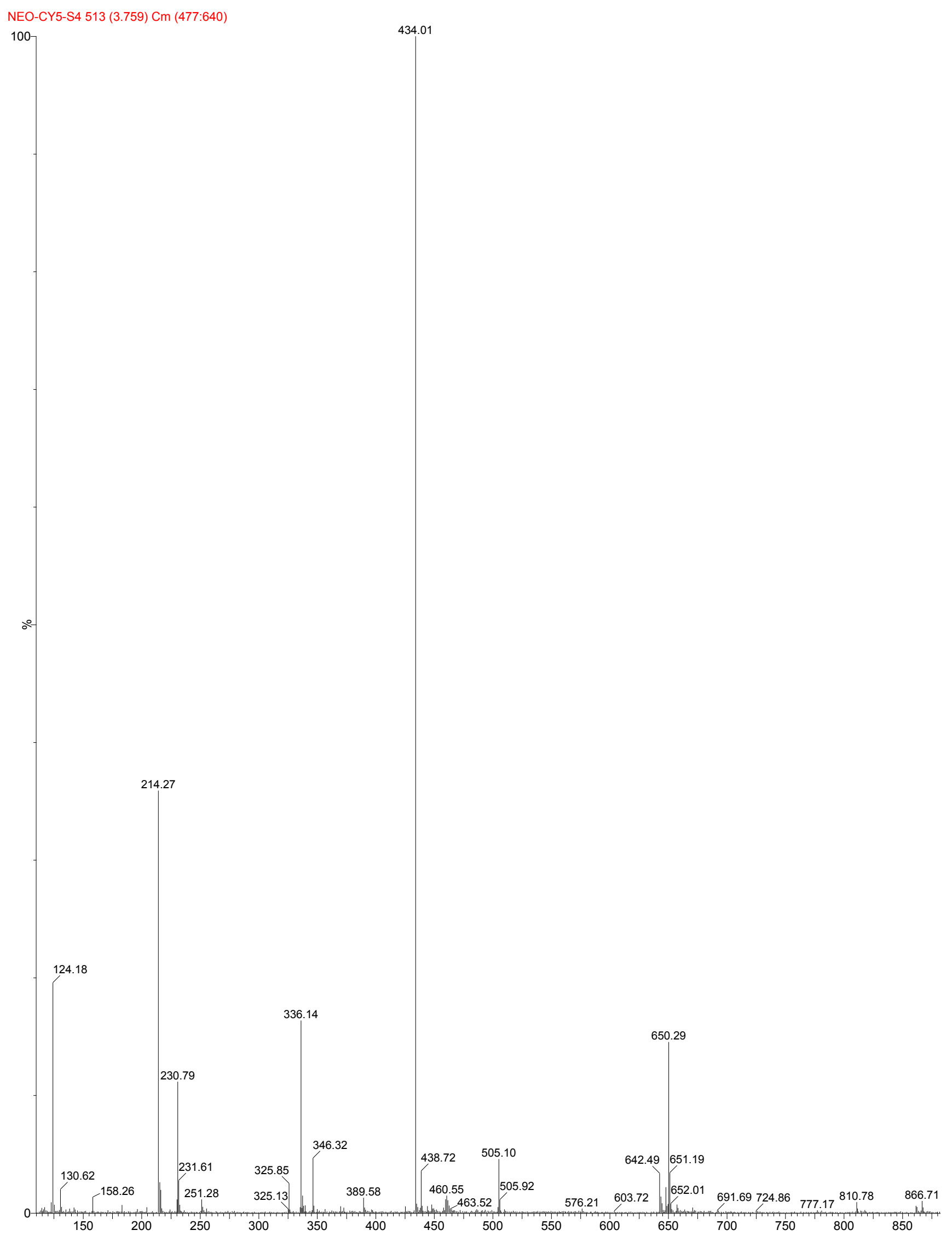




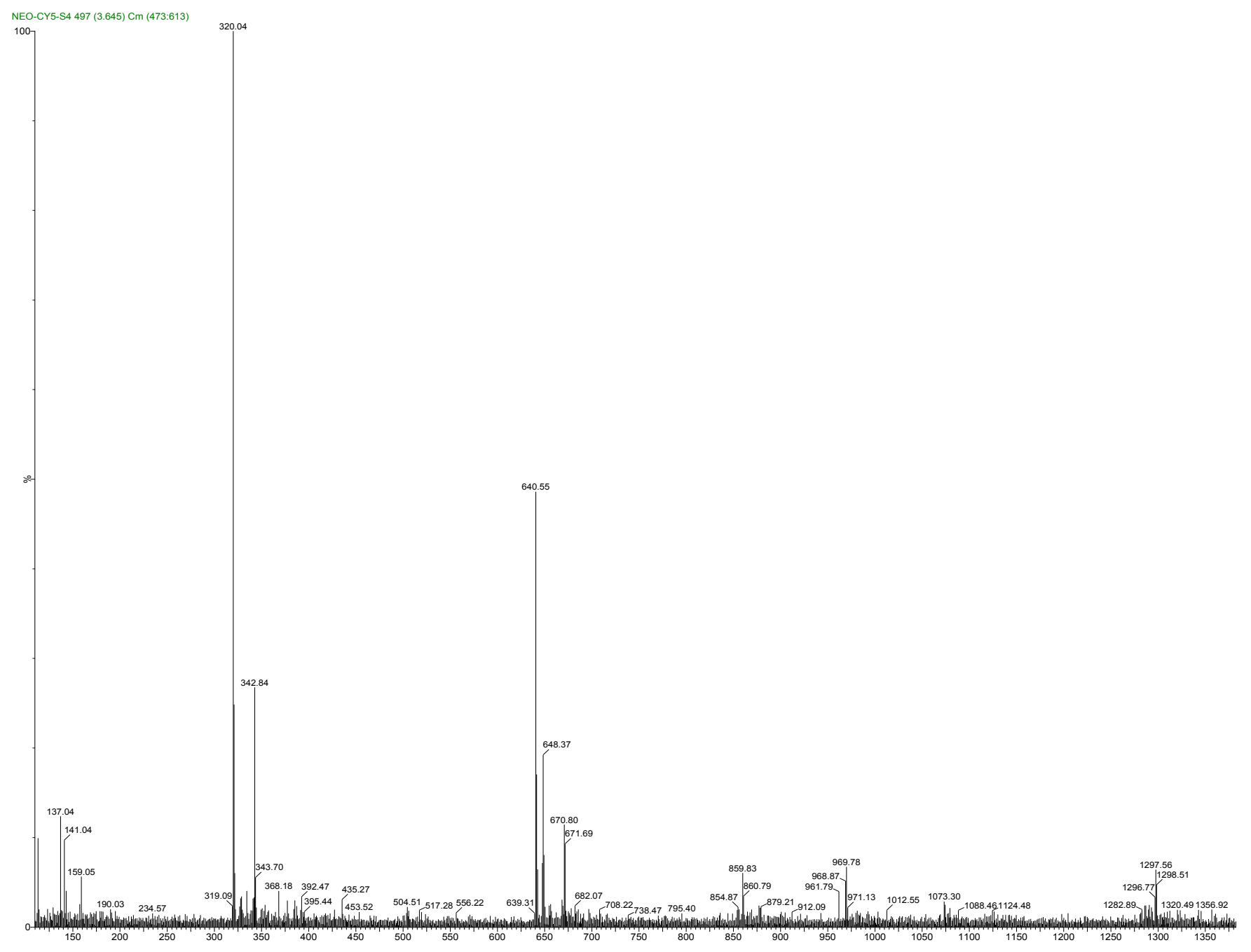

Figure S6. Characterization of Boc-neomycin derivative and Neo-Cy5. a) LC-MS of 2-Ntrifluoroacetamidoethylthio-neomycin derivative. b) LC-MS of deprotected 2-Ntrifluoroacetamidoethylthio-neomycin derivative. c) Analytical thin-layer chromatography of the Neo-Cy5 conjugate. After selective deprotection of the 5" position of Boc-neomycin, the free amino group was reacted with Cy5 monofunctional NHS-ester and the reaction monitored by TLC (silica gel 60 F254 plates; chloroform/Ethanol/ $\mathrm{NH}_{4} \mathrm{OH}$ 28\%/5.6:3.8:0.45). The results showed that reactions were complete. d) After purification on TLC plates (Silica gel 60, Merck), Neo-Cy5 was eluted and the purity verified again by TLC. c) LC-MS characterization of Neo-Cy5. e) LC-MS of the Neo-Cy5 conjugate (Cy5 from Lumiprobe, see Figure S5). 


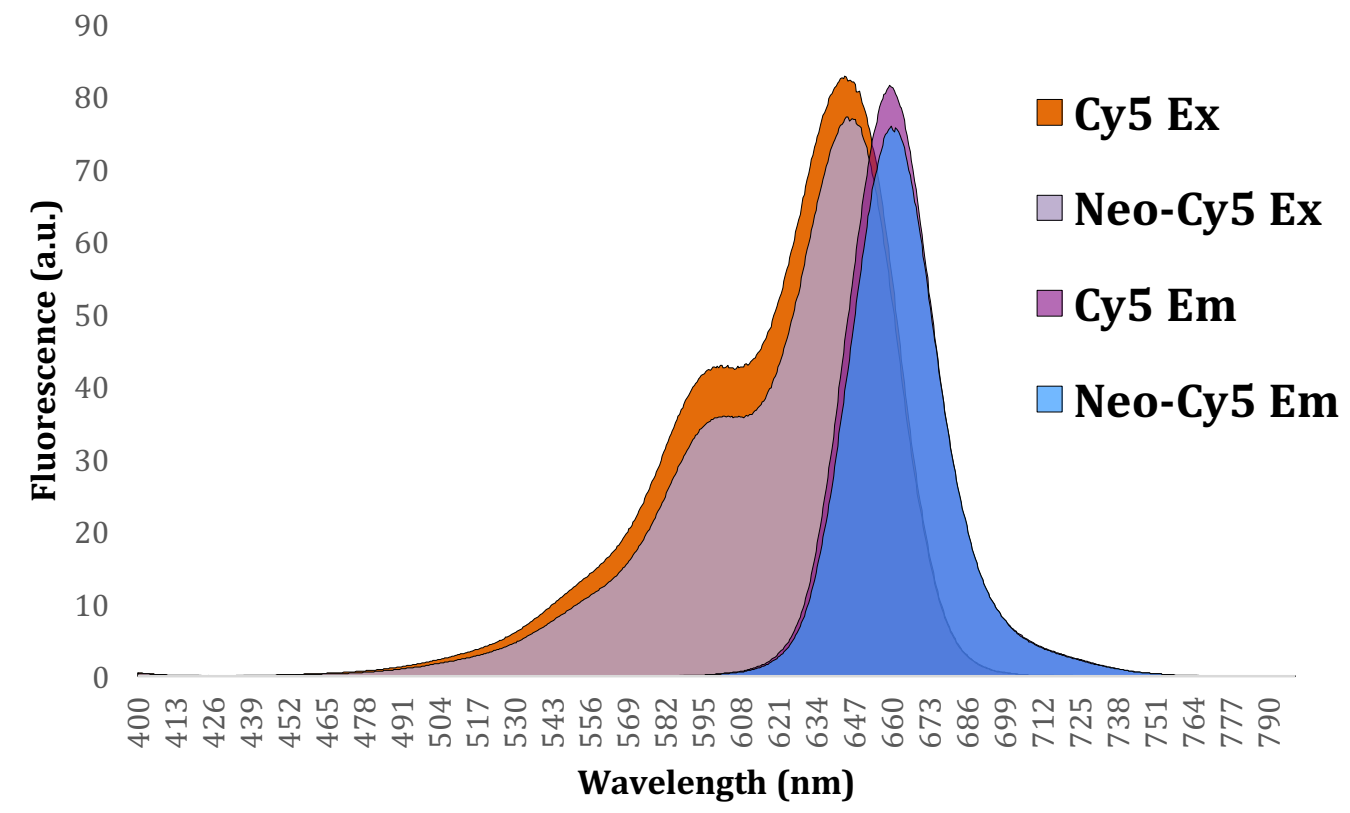

Figure S7. Excitation and emission spectra of Cy5 and Neo-Cy5. Data were recorded for $1 \mu \mathrm{M}$ solutions of $\mathrm{Cy} 5$ or Neo-Cy5 in Tris-HCl (pH 7.6). Optical properties are identical.
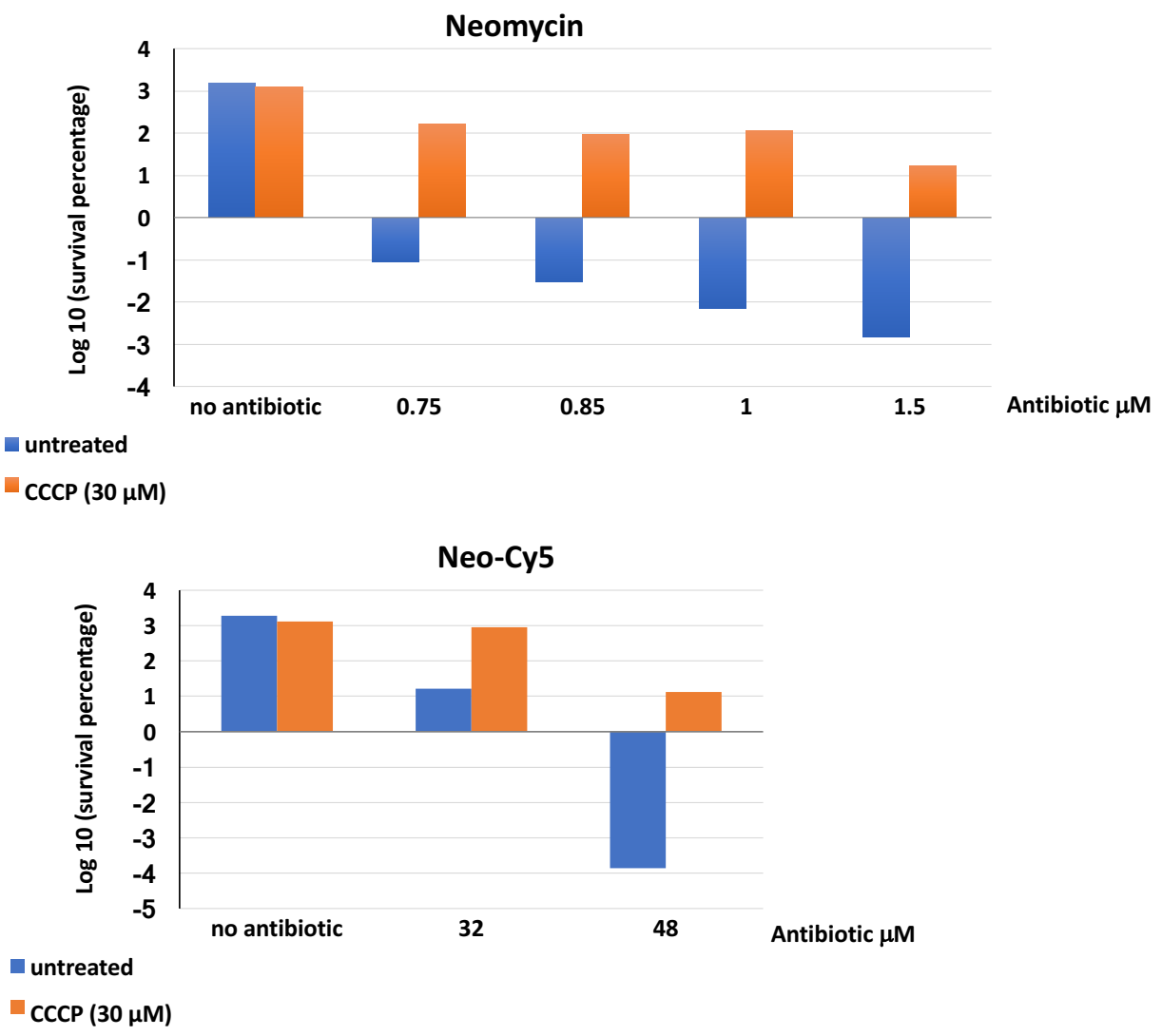

Figure S8. Neomycin and Neo-Cy5-induced cell killing is PMF dependent.

Representative experiments for survival of E. coli MG1655 cells after a 4.5-h treatment with various concentrations of neomycin and Neo-Cy5 with and without a 2-h preincubation with $30 \mu \mathrm{M}$ CCCP. Plotted are values relative to untreated control culture. 


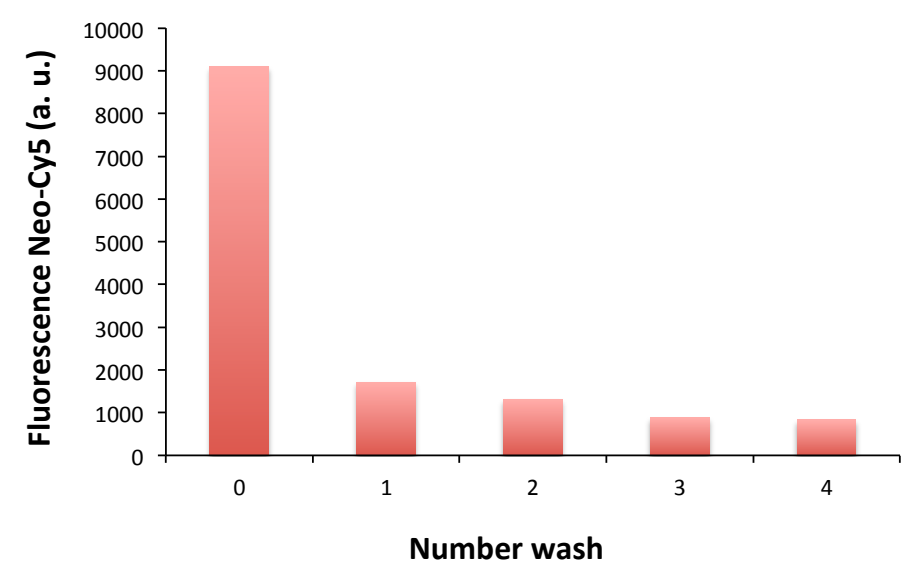

Figure S9. Excess Neo-Cy5 is removed by filtration. E. coli MG1655 cells (OD 6000.02 ) were incubated 5 minutes with $32 \mu \mathrm{M}$ Neo-Cy5 at $37^{\circ} \mathrm{C}$ then filtered through a $0.45-\mu \mathrm{m}$ pore-size HAWP membrane. Cells were washed or not with $100 \mu \mathrm{L}$ MOPS-G medium (pre-warmed to $37^{\circ} \mathrm{C}$ ), recovered from the filter, and immediately analyzed by FACS. The average of Neo-Cy5 signals for each sample was measured. Three washing steps were required to remove the Neo-Cy5.

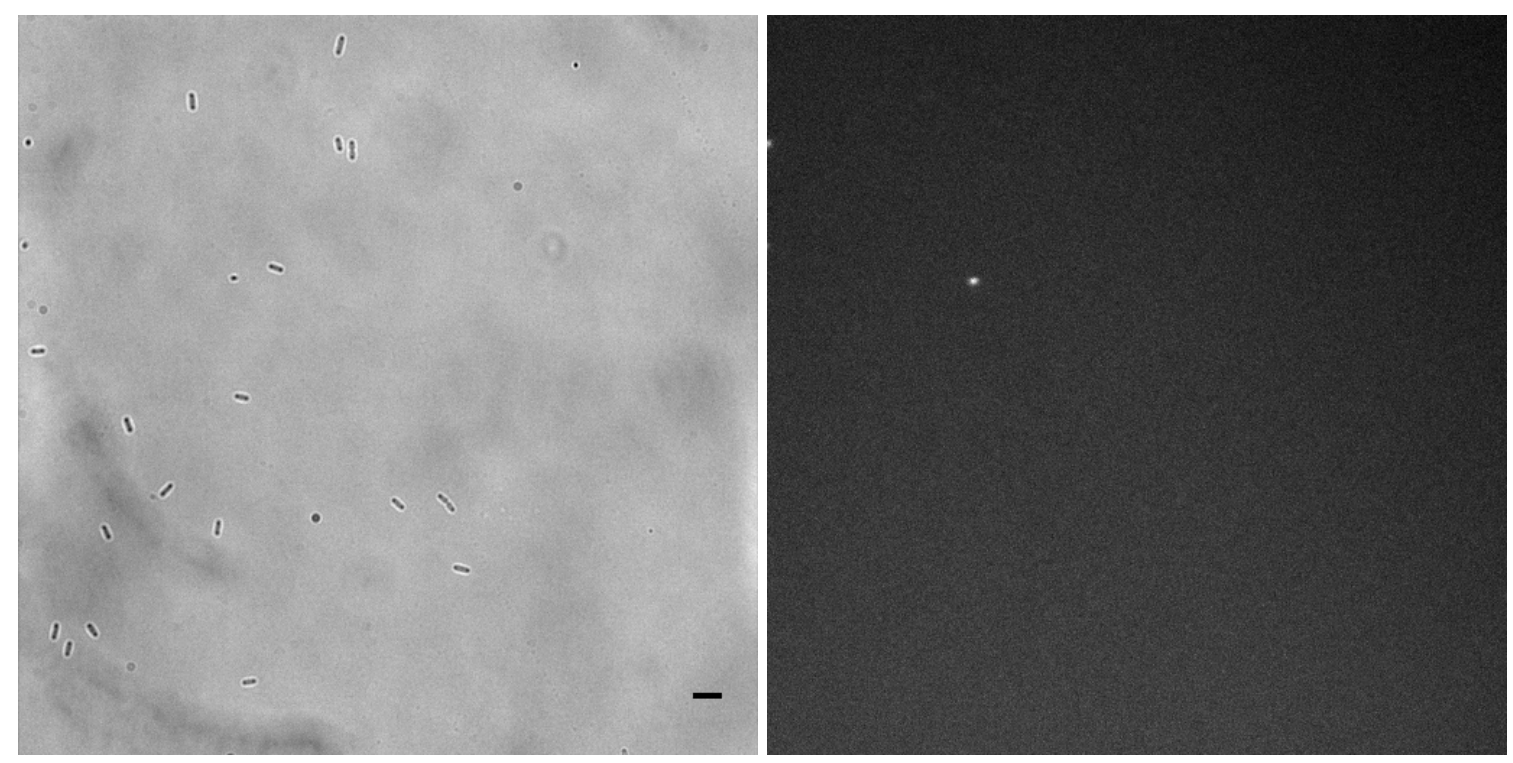

Figure S10. Cy5 does not enter live E. coli cells. Left: Transmitted light image of a field of E. coli MG1655 cells exposed to $32 \mu \mathrm{M}$ Cy5 for $1 \mathrm{~h}$ at $37^{\circ} \mathrm{C}$. Cells were washed on a 0.45 $\mu \mathrm{m}$-pore-size HAWP membrane filter. Right: Fluorescence image of the same field of view obtained with an electron-multiplying gain of 50 and an exposure of $50 \mathrm{~ms}$. 
Peripheral Neo-Cy5 and Spinach-ribosome

BF

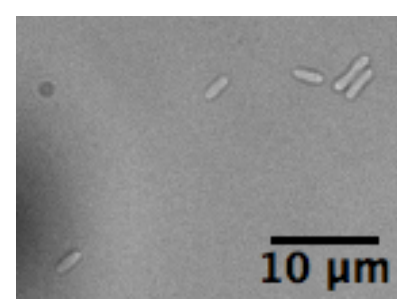

cy5

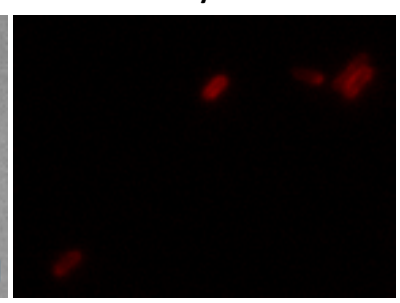

Spinach

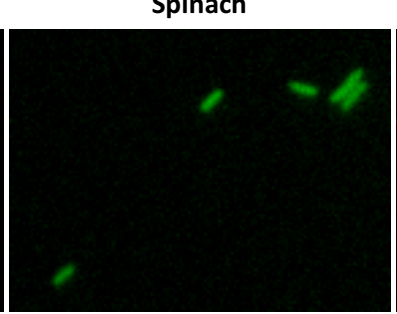

Cy5 + Spinach

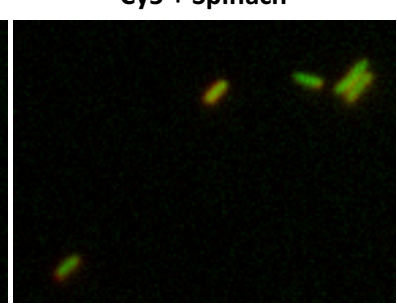

Figure S11. Neo-Cy5 does not localize with ribosomes after a 5-minute incubation. $E$. coli cells expressing Spinach-tagged ribosomes were exposed to Neo-Cy5 and imaged. Cells were illuminated with a 642-nm laser for Neo-Cy5 excitation and emission was detected at $670 \mathrm{~nm}$. Spinach aptamer bound to DFHBI was excited with a mercury lamp, and images were acquired with a GFP filter cube (ex. $470 \pm 20 \mathrm{~nm}$, em. $525 \pm 25 \mathrm{~nm}$ ). Brightfield, Neo-Cy5 (red), Spinach (green), and merged images.

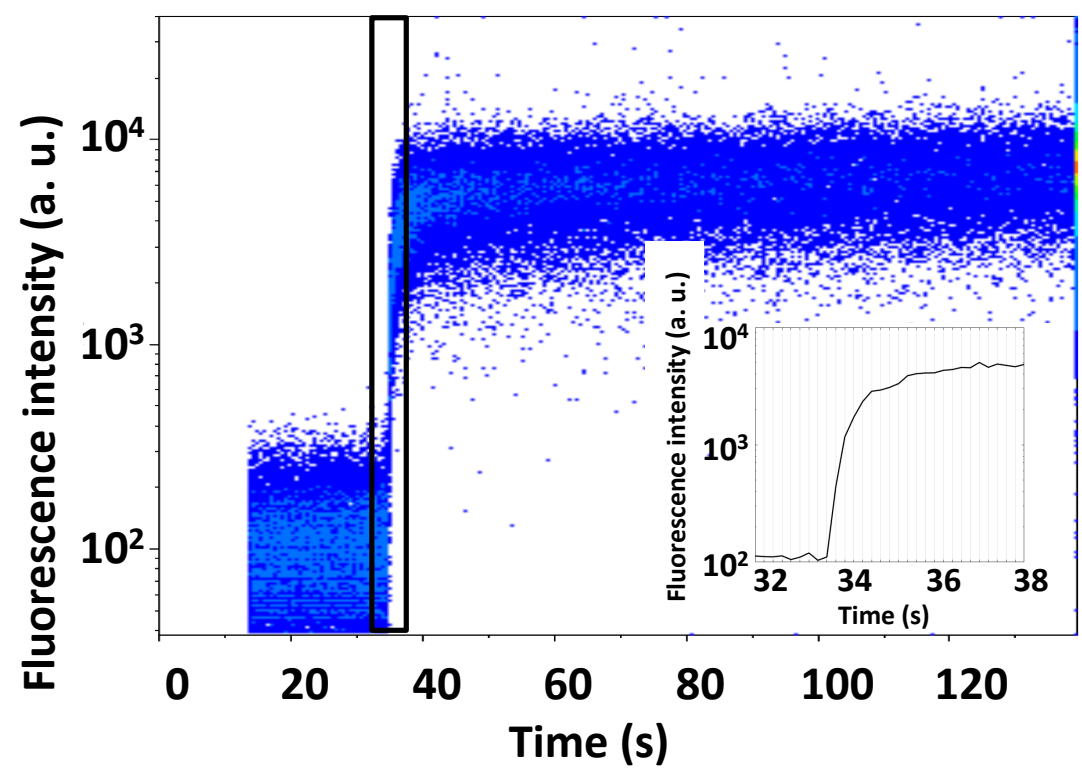

Figure S12. Fast kinetics of Neo-Cy5 interaction with the membranes revealed by realtime FACS experiments. Cells in exponential growth phase $\left(0.3 \mathrm{OD}_{600}\right)$ were diluted 20 fold to a volume of $150 \mu \mathrm{L}$ and placed into the flow cytometer for analysis at $37^{\circ} \mathrm{C}$. FACS analysis was initiated and, after a delay of $20 \mathrm{~s}, 500 \mu \mathrm{L}$ of Neo-Cy5 solution was added for a final concentration of $0.4 \mu \mathrm{M}$. Addition of the drug diluted the cells to $0.003 \mathrm{OD}_{600}$. Fluorescence intensities of individual cells are plotted vs. time. Inset represents the integration of the fluorescence signals within the boxed area. The signals were average over 200-ms intervals during this 6-s time period. 

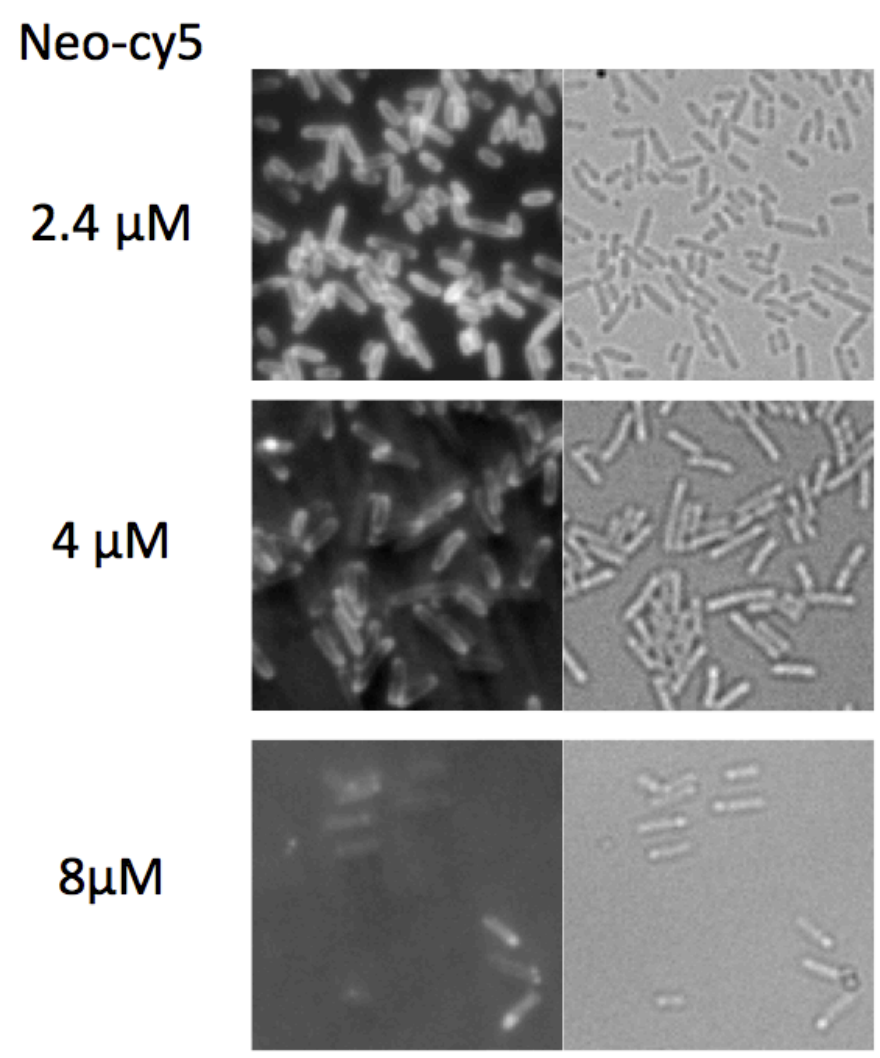

Figure S13: Neo-Cy5 induces morphological defects in E. coli cells grown overnight in M9 glucose $(0.4 \%(\mathrm{w} / \mathrm{v}))$. Bright-field images are displayed on the right and fluorescence images on the left. At a concentration of $4 \mu \mathrm{M}$, cells are longer and at $8 \mu \mathrm{M}$, foci are observed at poles. 


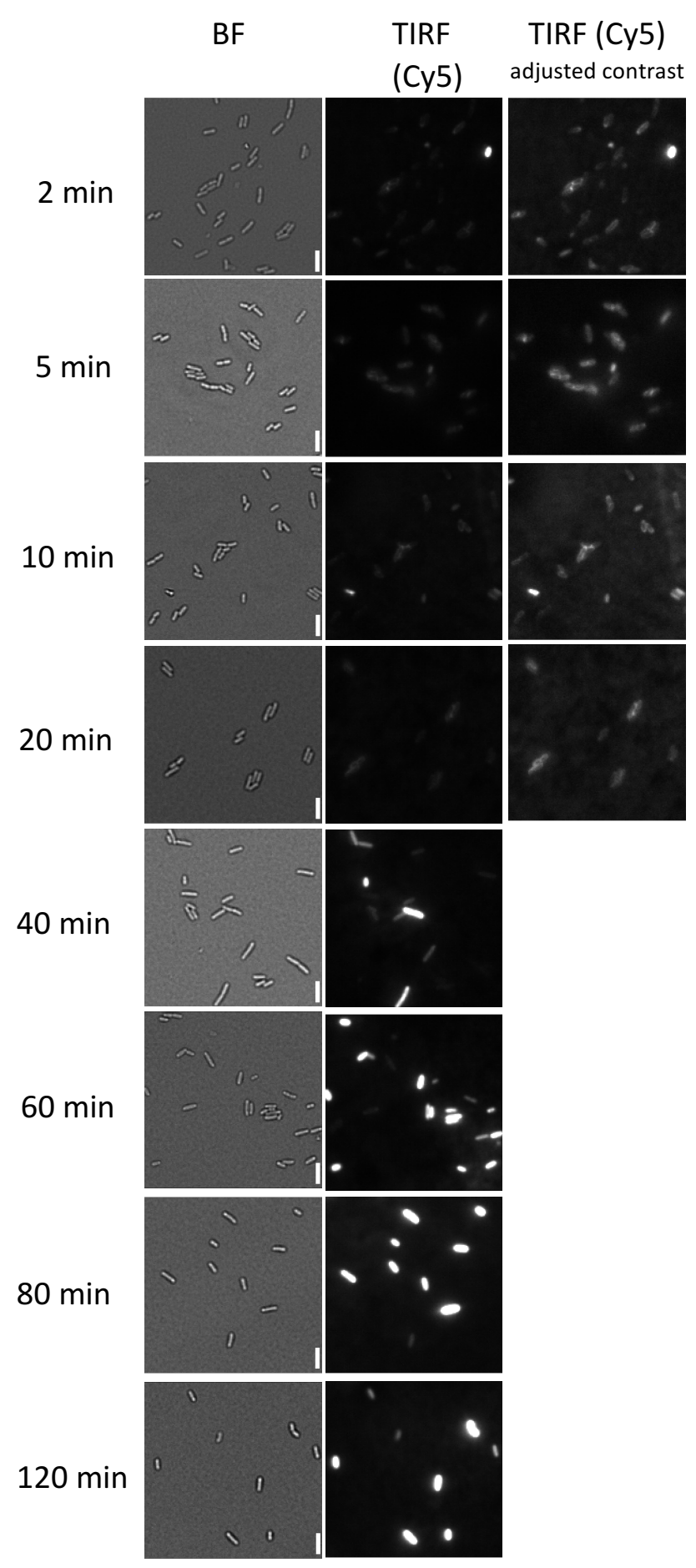

Figure S14: Time-course experiment of changes in Neo-Cy5 accumulation levels. Fast growing cells $\left(\mathrm{OD}_{600}\right.$ : 0.02$)$ were incubated at $37{ }^{\circ} \mathrm{C}$ with Neo-Cy5 $(32 \mu \mathrm{M})$. At each time points cells were washed on filter and then observe directly on MOPS-G agarose pad (Scale bar: $5 \mu \mathrm{m}$ ). Images were scaled to the minimum and maximum pixel values of the first image $t=2 \mathrm{mn}$. For the first 4 time points, contrast was adjusted for better visualization and displayed on the right column. For each time point, images were analyzed with microbeJ for quantification of Cy5 signals to generate figure 5 panel $\mathrm{d}$. 